\title{
Influence of Moisture Content on the Structural Characteristics of Argillaceous Weakly Consolidated Rock Caused by Dynamic Loading in the Coal Mine
}

\author{
Lingdong Meng, Lijun Han $\mathbb{D}$, Hexuan Zhu, Wenlong Dong, and Wei Li \\ State Key Laboratory for Geomechanics and Deep Underground Engineering, China University of Mining and Technology, \\ Xuzhou 221116, China \\ Correspondence should be addressed to Lijun Han; hanlijun@cumt.edu.cn
}

Received 11 June 2021; Revised 8 August 2021; Accepted 11 August 2021; Published 26 August 2021

Academic Editor: Yi Bao

Copyright (c) 2021 Lingdong Meng et al. This is an open access article distributed under the Creative Commons Attribution License, which permits unrestricted use, distribution, and reproduction in any medium, provided the original work is properly cited.

\begin{abstract}
The argillaceous weakly consolidated rock is a kind of soft rock that will bring great difficulties in the construction process. Specimens of such rock under different moisture contents are taken as the research object. By the Hopkinson pressure bar test (SHPB), the structural and mechanical characteristics of the rock under dynamic impact are analysed. With increasing moisture content, the transmitted wave amplitude decreases gradually, which indicates that the higher the moisture content of the rock is, the easier it is to deform under dynamic impact and the greater its plasticity. The boundary between plastic failure and brittle failure is $10 \%$ moisture content. Through a mercury injection test, the porosity variation is analysed. The porosity of the rock decreases with increasing moisture content after the same dynamic impact. The porosity curve can be roughly divided into two sections with a moisture content of $15 \%$ as the boundary. Based on a uniaxial compression test, the elastic modulus, peak strength, and residual strength of specimens after dynamic impact are analysed, and the mechanical properties of the rock are revealed. Its mechanical properties can be divided into three sections with a moisture content of $9.18 \%$ and $15.19 \%$, and each section has obvious differences.
\end{abstract}

\section{Introduction}

Due to the development of economy, there is a great demand for energy. As the main energy source in China, the main coal-producing areas are transferred to Inner Mongolia, Xinjiang, and other areas [1]. Argillaceous weakly consolidated rock is widely distributed in the new production areas with characteristics such as poor cementation, low strength, and a tendency for weathering $[2,3]$. What is recognized by academia is that such rock has a tendency to absorb water and become slimy under high-humidity conditions and lose water and to weather under low-humidity conditions.

For an argillaceous weakly consolidated rock mass, its physical and mechanical properties are mainly affected by the content of clay minerals in the rock mass. Clay minerals mainly include kaolinite, illite, montmorillonite, and I/S mixed-layer structures $[4,5]$. The difference in the crystal structure of clay minerals makes rock masses exhibit different mechanical properties. For example, montmorillonite can very easily expand after absorbing water.

Another important factor is moisture content to lowering the strength of rocks, especially rocks with a high clay mineral content, such as argillaceous weakly consolidated rock [6, 7]. A small increase in the moisture content may lead to marked reductions in strength and deformability. In addition, for underground construction, determining the effect of the moisture content on rock strength is of prime importance [8-10].

A number of investigations on moisture content on the mechanical properties of rock materials have been carried out by domestic and international scholars. Hawkins studied the effect of moisture content on the sandstones' uniaxial compressive strength in Britain [11]. Vales studied the influence between the degree of saturation and the physical-mechanical properties of Tournemire shale. His research showed that the 
mechanical behaviour is sensitive to the saturation state. Vásárhelyi suggested that the petrophysical properties of rock decrease with increasing moisture and that this can lead to an increase in mechanical property and showed a method for assessing the sensitivity of sandstone to moisture content [12]. Erguler analysed water-induced variations in the mechanical properties of clay-bearing rocks and developed a method for estimating the rock strength and deformability at any moisture content based on physical properties [13]. Meng studied the mechanical properties and influencing factors of mudstone in coastal coal measures and proposed that the compressive strength and elastic modulus of mudstone decrease with the increase of water content [14]. Li et al. experimented to study on the softening characteristics of mudstone in relation to moisture content [15] and showed that moisture content has a significant effect on shear properties reduction of mudstone and stress concentration is negatively correlated with moisture content. Wang investigated the pore structure and water imbibition behaviour through the mercury injection experiment [16] and proposed that the expansion deformation can be controlled by strengthening the lateral restraint. Kovalenko studied the failure of rock under dynamic loading and suggested an algorithm for calculating the failure zones that allows the geometric position and size of the zone to be determined and sheds light on the mechanism by which failure appears and develops over time [17]. Yang et al. investigated the dynamic response of a slope under the action of seismic loading using shaking table tests and proved that slopes composed of unsaturated soil with different moisture contents have different instability modes [18].

The characteristics of soft rock and hard soil make the stability of this kind of rock poor $[19,20]$. After the excavation of rock roadway, the disturbance load in the construction process makes the cracks in the rock develop, resulting in a sharp decline in the mechanical properties of the rock. The research on the safety of the tunnel in argillaceous weakly cemented rock has also attracted the attention of many scholars [12, 21-23]. From experimental and theoretical research perspectives, such rock exhibits unstable mechanical properties [24, 25].

Little research has been performed on the mechanical properties of argillaceous weakly consolidated rock under dynamic loading $[26,27]$. In this paper, specimens with different moisture contents were prepared first, and then the dynamic mechanical properties and the constitutive relationship of the argillaceous weakly consolidated rock mass under dynamic loading were studied by the Hopkinson pressure bar test. Through a mercury injection test, the variation in the porosity of argillaceous weakly consolidated rock mass under different moisture content states was analysed. Through a uniaxial compression test, the elastic modulus, peak strength, and residual strength of such rock under different moisture content conditions after dynamic impact were analysed.

\section{Materials and Methods}

2.1. Materials. The test specimens are obtained from the West $1^{\text {st }}$ coal mine of China Resources Power. The sampling depth is $310 \mathrm{~m}$. According to the engineering geological data, the area is mainly composed of Cretaceous mudstone, which is characterized by poor cementation $[28,29]$. According to the color, there are grey mudstone and black mudstone, as shown in Figure 1.

As an efficient and accurate testing method, X-ray diffraction (XRD) is widely used in the analysis of rock and mineral composition [30-32]. In this study, the rock specimens were subjected to XRD analysis and testing at the Modern Analysis and Calculation Center of China University of Mining and Technology and the Yanyuan Microstructural Analysis and Testing Center in Beijing. The scanning contents included qualitative and quantitative analyses of whole-rock minerals and clay minerals. Four directional slices ( $\mathrm{N}$ slice, natural directional slice; $\mathrm{T}$ slice, high-temperature slice; E slice, ethylene glycol saturated slice; and $\mathrm{H}$ slice, hot dilute hydrochloric acid-treated slice) were made by centrifugal method, and the quantitative analysis results of clay minerals were obtained by combining with the analysis results of whole-rock mineral composition. The XRD diffraction patterns of the specimens are shown in Figure 2. The analysis of rock specimens shows that the loose density is $0.73 \mathrm{~g} \cdot \mathrm{cm}^{-3}$, the density is $1.13 \mathrm{~g} \cdot \mathrm{cm}^{-3}$, the plastic limit is $27.1 \%$, and the liquid limit is $34.5 \%$. The natural moisture content of rock specimens is approximately $14.7 \%$.

The standard specimen used in the test should meet the size requirement, and the end face should be smooth and flat. The standard specimen required for the test in this paper is $50 \mathrm{~mm} \times 50 \mathrm{~mm}$. The specimens were cut to a height of $51 \mathrm{~mm}$, and then two end face grinding machines were used to polish the specimen to a height of $50 \mathrm{~mm}$. The size should meet the GB/t50266-2013 "Engineering Rock Mass Test Method Standard."

To study the influences of moisture content on the mechanical properties of argillaceous weakly consolidated rock, the specimens were divided into six groups of 3 for each group according to the different moisture contents, as shown in Table 1.

A set of self-developed test systems have been used to study the evolution of water loss in argillaceous weakly consolidated rock mass [33]; these systems are mainly composed of a constant temperature and humidity maintenance box, a temperature and humidity control and monitoring control system, and a moisture content monitoring and recording system. For the testing performed in this paper, the specimens with different moisture contents should be preserved. Therefore, a constant temperature and constant humidity curing chamber, temperature and humidity controls and monitoring, and moisture content monitoring and recording system are mainly used in the test. The moisture content of each sample was cured to $6 \%, 9 \%$, $12 \%, 15 \%, 18 \%$, and $21 \%$ through the curing box.

\subsection{Methods}

2.2.1. Dynamic Impact Test by Hopkinson Pressure Bar Tests. The mechanical properties of argillaceous weakly cemented rock under dynamic impact are studied, and the influences of moisture content are examined. As an efficient and 


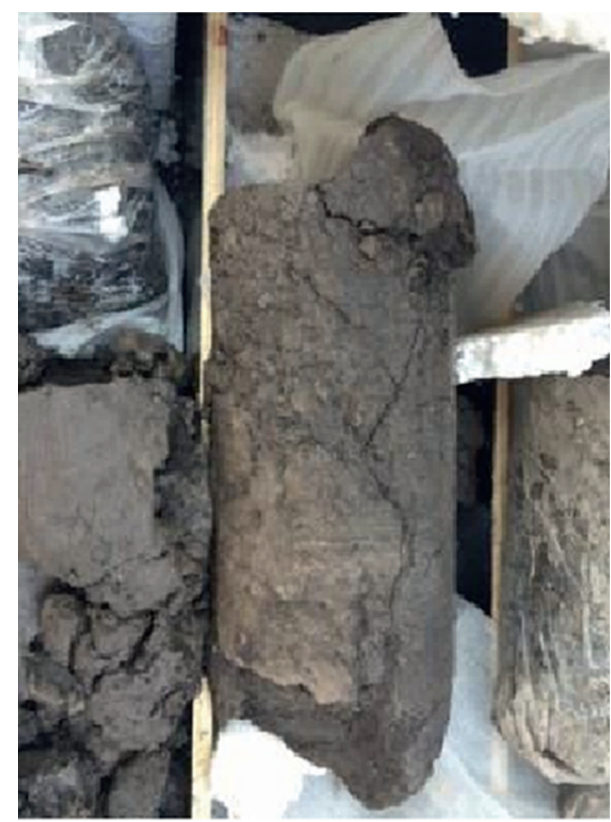

(a)

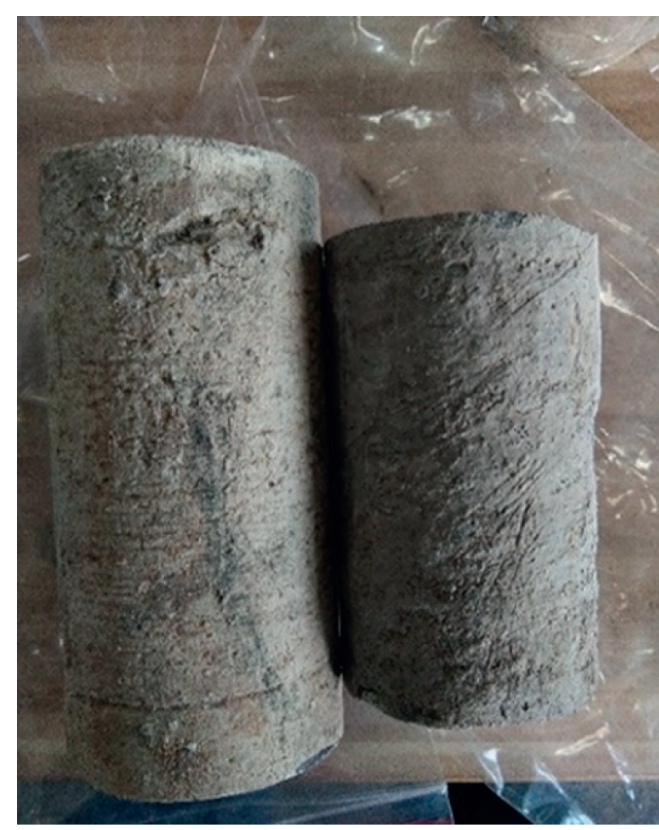

(b)

FiguRE 1: The argillaceous weakly consolidated rock specimens obtained in primary strata: (a) black mudstone, and (b) grey mudstone.

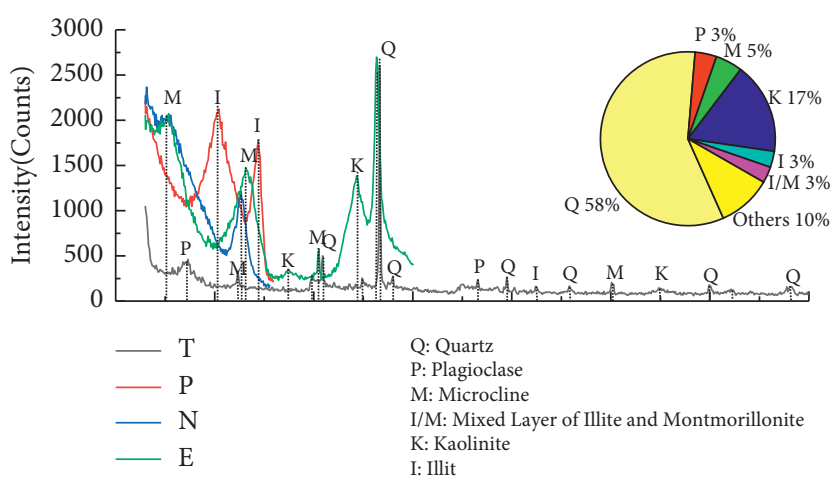

FIGURE 2: The XRD diffraction diagrams of the argillaceous weakly consolidated rock specimens.

TABLE 1: The gradient moisture content for argillaceous weakly consolidated rock specimens.

\begin{tabular}{|c|c|c|c|c|c|c|c|c|c|c|c|c|c|c|c|c|c|c|}
\hline Group & \multicolumn{6}{|c|}{ G1 } & \multicolumn{6}{|c|}{ G2 } & \multicolumn{6}{|c|}{ G3 } \\
\hline Number & $\mathrm{S}_{1}$ & $\mathrm{~S}_{4}$ & $\mathrm{~S}_{7}$ & $\mathrm{~S}_{10}$ & $\mathrm{~S}_{13}$ & $\mathrm{~S}_{16}$ & $\mathrm{~S}_{2}$ & $\mathrm{~S}_{5}$ & $\mathrm{~S}_{8}$ & $\mathrm{~S}_{11}$ & $\mathrm{~S}_{14}$ & $\mathrm{~S}_{17}$ & $\mathrm{~S}_{3}$ & $\mathrm{~S}_{6}$ & $\mathrm{~S}_{9}$ & $\mathrm{~S}_{12}$ & $S_{15}$ & $\mathrm{~S}_{18}$ \\
\hline Moisture (\%) & 6 & 9 & 12 & 15 & 18 & 21 & 6 & 9 & 12 & 15 & 18 & 21 & 6 & 9 & 12 & 15 & 18 & 21 \\
\hline Purpose & \multicolumn{6}{|c|}{ SHPB } & \multicolumn{6}{|c|}{ Mercury injection test after SHPB } & \multicolumn{6}{|c|}{$\begin{array}{l}\text { Uniaxial compression test after } \\
\text { SHPB }\end{array}$} \\
\hline
\end{tabular}

accurate testing method, a split Hopkinson pressure bar (SHPB) is widely used in the mechanical properties of rock under dynamic load [34-36].

The SHPB test principle is based on the one-dimensional elastic wave hypothesis and stress uniformity hypothesis $[37,38]$. In the one-dimensional elastic wave theory, it is assumed that the pressure bar in the test device is in the elastic state, the elastic modulus of the pressure bar is $E$, and the density is $\rho$. Then, the disturbance generated at the end of the rod will propagate along the rod at the wave speed of $C_{0}=\sqrt{E / \rho}$. When the incident wave $\varepsilon_{i}$ is transmitted to the other end of the incident rod, the incident rod collides with the sample, which leads to the impedance of the stress wave, resulting in reflection and transmission. In the incident rod, there is a reflected wave $\varepsilon_{r}$ which returns along the original path, and in the transmission rod, there is also a transmitted 


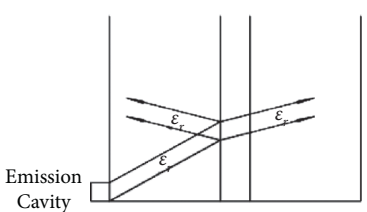

(a)

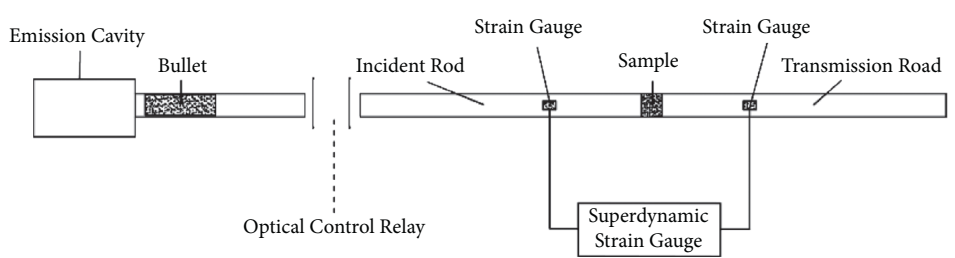

(b)

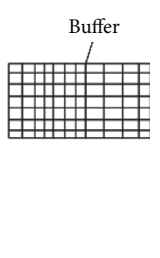

Buffer

FiguRe 3: SHPB experimental facility.

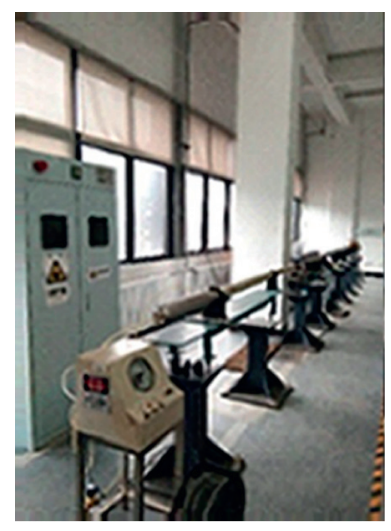

(a)

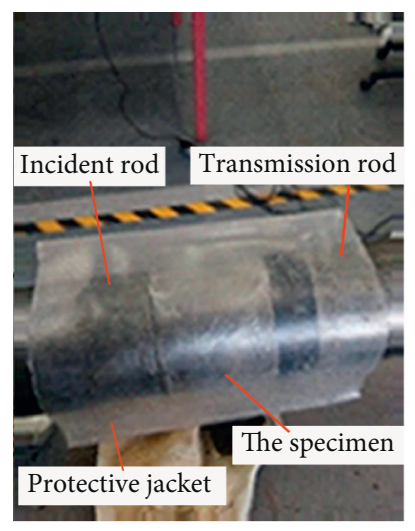

(b)

FIgURE 4: Layout of the SHPB experiment specimens. (a) SHPB apparatus. (b) Layout of specimens.

wave $\varepsilon_{t}$ which continues to pass forward [39]. The propagation process of the stress wave in the whole strut device is shown in Figure 3(a).

The conventional SHPB device consists of a transmission rod, a transmitting cavity, a punch, an incident rod, a data acquisition system, and an absorption device, as shown in Figure 3(b).

In this paper, the SHPB system of the Modern Analysis Center in CUMT is used. The incident rod and transmission rod are $2000 \mathrm{~mm}$ in length and $50 \mathrm{~mm}$ in diameter, and the punch is $400 \mathrm{~mm}$ in length and $50 \mathrm{~mm}$ in diameter. The layout of the SHPB experiment specimens is shown in Figure 4 . The dynamic impact mechanical properties of the above rock under different moisture contents are studied in this experiment, and the impact pressure is set to $0.5 \mathrm{MPa}$.

2.2.2. Mercury Injection Experiment. The porosity of a rock mass can be measured by a mercury injection experiment $[40,41]$. The mercury injection method is mainly based on the capillary bundle model. It is assumed that the porous medium is composed of capillary bundles with different diameters. Mercury does not wet the surface of a pore in a rock, which indicates that it is a nonwetting phase. Comparatively speaking, the air or mercury vapour in the rock pore is a wetting phase. To inject mercury into the pores of rocks is to displace the wetted phase with the nonwetting phase. When the injection pressure is higher than the capillary pressure corresponding to the pore throat, mercury enters the pore. At this time, the injection pressure is equivalent to the capillary pressure, and the corresponding capillary radius is the pore throat radius. The volume of mercury entering the pore is the pore volume connected by the throat. The pore distribution curve and capillary pressure curve can be obtained by changing the injection pressure continuously [42]. The calculation formula is

$$
p_{c}=\frac{2 \sigma \cos \theta}{r} \text {. }
$$

In formula (1), $P_{c}$ is capillary pressure, $\mathrm{MPa} ; r$ is pore radius, $\mu \mathrm{m} ; \sigma$ is interfacial tension between mercury and air, $\sigma=480 \mathrm{dyn} / \mathrm{cm}$; and $\theta$ is wetting angle between rock and mercury, $\theta=140^{\circ}, \cos \theta=0.765$.

The capillary pressure $r$ is

$$
r=\frac{0.735}{p_{c}} .
$$

In this paper, mercury injection was performed at Beijing Ocean Huanyu Petroleum Technology Co., Ltd., and the mercury injection test instrument used was the Corelab CMS300 and Auto Pore IV 9505 mercury injection apparatus produced by CoreIab Core Company in the USA. The experiment was carried out by professionals, and the specimens were dried to a constant weight at $105^{\circ} \mathrm{C}$ before testing the porosity. The mercury injection test mainly includes two processes of pressurized mercury admission and decompression, and the maximum experimental pressure is $200 \mathrm{MPa}$.

The mercury injection test was carried out in accordance with the standards of the PRC. The implementation 
standards mainly included SY/T5336-2006 "Core Conventional Analysis Methods" and SY/T5346-2005 "Determination of Rock Capillary Pressure Curve."

\subsubsection{Uniaxial Compression Experiment. Argillaceous} weakly consolidated rock masses have low compressive strength, high plasticity, and changeability under a high moisture content, so the pressure machine should have the characteristics of a small range, high precision, and ease of operation when selecting and testing its mechanical properties $[10,43]$. Comprehensive consideration is desired, so this test uses a MTS-816 material testing system (produced by Shanghai Precision Instrument Co., Ltd). As shown in Figure 5, this system consists of the precision of an automatic control and data acquisition system and implements the data collection and control process with a fully digital adjustment. In the experiment, the computer starts working automatically according to the test parameters set at the beginning of the calculation and simultaneously displays the corresponding experimental results. The MTS-816 material testing system's maximum test force is $100 \mathrm{kN}$, the measuring range is $2 \% \sim 100 \%$, and the accuracy is $1 \%$.

The test process and test method are as follows:

Use a knife to smooth the end face of the specimen after the SHPB test, and then use a Vernier calliper to measure the diameter and height of the specimens. Due to the impact power, there are different deformations of the specimen diameter. The diameter should be measured at the top, bottom, and middle, and then the arithmetic average should be calculated.

Put the specimen in place, and adjust the indenter to the proper position. To eliminate the hoop effect on the end face, apply Vaseline to the end face of the sample to reduce friction, and place the sample in the centre of the loading platform of the testing machine.

The experimental control system adopts the mode of the axial displacement control system; the upper limit of axial displacement is set to $20 \mathrm{~mm}$, and the loading speed control is set to $0.1 \mathrm{~mm} / \mathrm{min}$ until the specimens are destroyed or the axial displacement reaches the upper limit.

2.2.4. Moisture Content Test of the Specimens. The moisture content of the specimens after test is determined by the drying method. The initial mass of the specimens is recorded as moi $(i: 1,2,3, \ldots)$. The specimens are placed in a drying box, the temperature is set at $105^{\circ} \mathrm{C}$, and the specimens are dried for at least $8 \mathrm{~h}$. After the drying requirements are met, the sample is cooled and weighed, and the mass is recorded where mdi $(i: 1,2,3, \ldots)$. The average water content $w_{i}$ is obtained by the following formula:

$$
w_{i}=\frac{m_{o i}-m_{d i}}{m_{d i}} \times 100 \%, \quad i=1,2,3 \ldots
$$

During the test, the change in water absorption can be dynamically monitored by the load cell. According to the relationships among the mass moisture content $\omega$, volume $V_{s}$, and mass $m_{s}$, the volumetric water content $\omega_{v}$ of mudstone is calculated using formula (3).

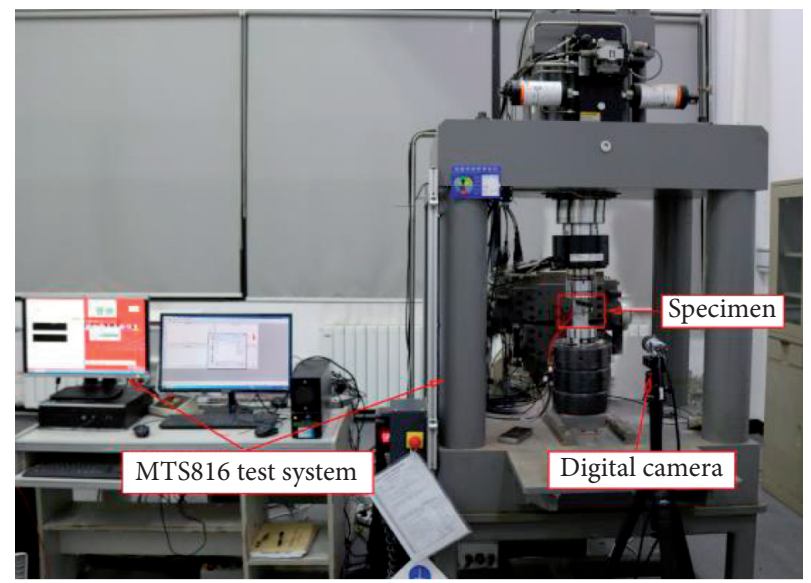

FIGURE 5: MTS-816 material testing system.

\section{Results}

\subsection{Analysis of the SHPB Test Results}

3.1.1. Waveform Analysis of Different Moisture Contents in SHPB Tests. When the incident wave passes through the contact surface between the rock specimen and the incident rod, a part of the wave passes through the rock sample to form a transmission wave. The other part is reflected and formed a reflection wave at the same time [44]. Because the incident wave will lose part of the energy when it propagates in the specimen, the amplitude of the transmitted wave is obviously smaller than that of the incident wave propagating in the incident rod.

Since Davies analysed the cause and propagation of Pochhammer-Chree oscillation in SHPB [45], scholars gradually adopt the method of smoothing the incident wave to eliminate the high-frequency oscillation of the incident wave as much as possible. A smooth incident wave is helpful to improve the uniformity of early stress. Its rise time can be widened appropriately. The uniform distribution of stress in the specimen can be realized in the rising section of the incident wave. And it can keep the stress uniform state for a longer time.

The moisture content of argillaceous weakly consolidated rock is the only variable. It can be seen from Figures 6 and 7 that when the impact pressure is constant, the amplitude of the strain wave in the incident rod is basically the same, and the value of the strain wave entering the transmission rod after passing through the specimen decreases with increasing moisture content. When the moisture content of the specimen is $6.63 \%$, the amplitude of the strain wave of the transmitted wave is $554.8 \mu \mathrm{m}$. When the moisture content is $9.22 \%, 11.91 \%, 15.37 \%$, $18.65 \%$, and $21.73 \%$, the corresponding transmission amplitude values are $496.4 \mu \mathrm{m}, 408.8 \mu \mathrm{m}, 311.2 \mu \mathrm{m}$, $248.2 \mu \mathrm{m}$, and $219 \mu \mathrm{m}$, respectively. When the moisture is $6.63 \%$, the specimen exhibits a certain brittleness. Combined with the analysis of specimen morphology, it can be seen that the specimen does not experience plastic deformation but is damaged by impact when it is impacted by the dynamic force at this moisture content. With 


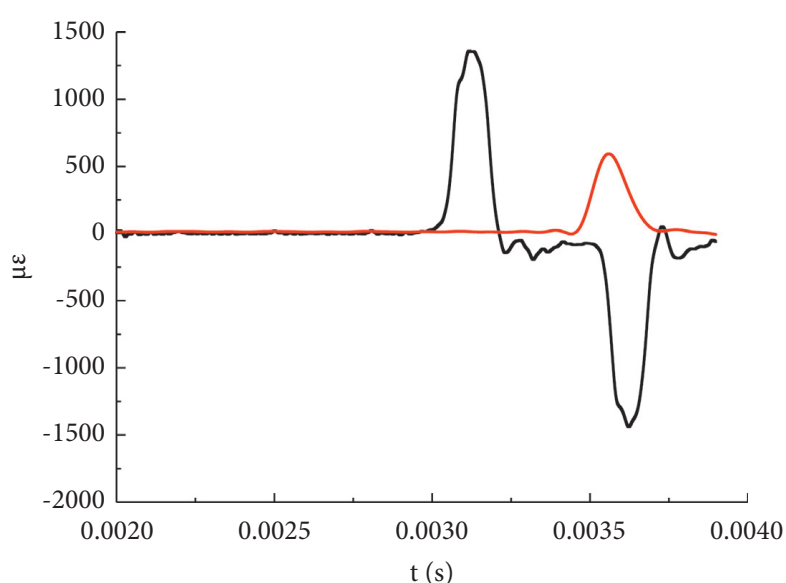

(a)

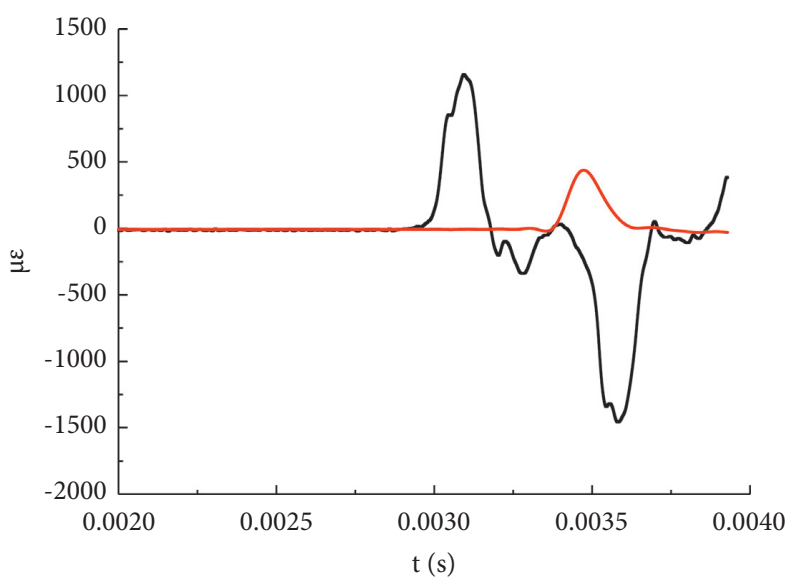

(c)

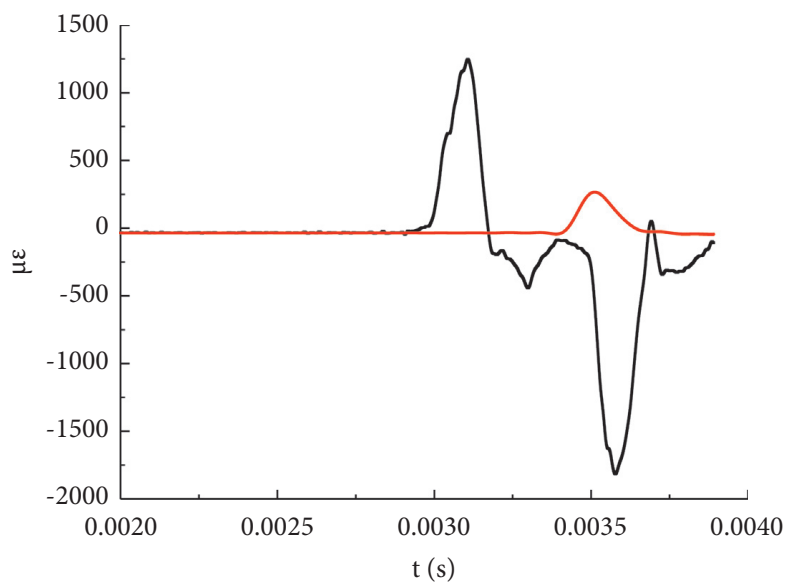

(e)

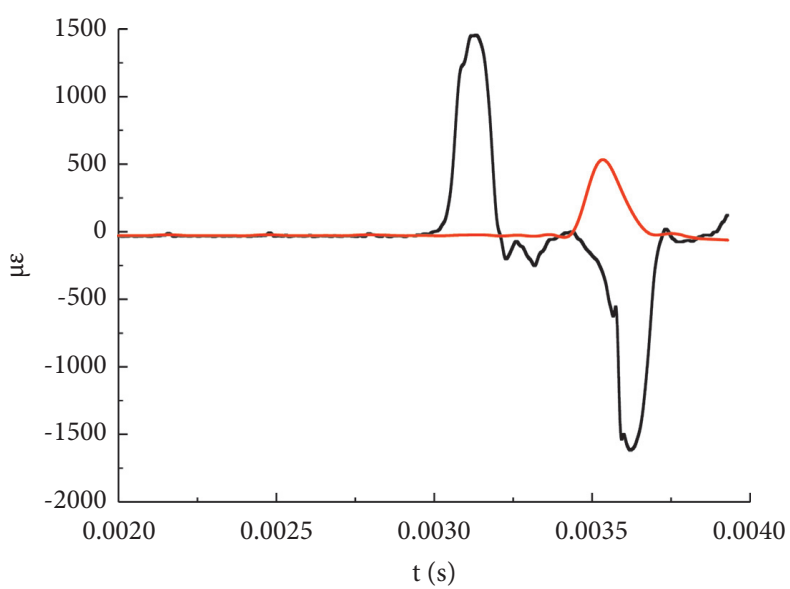

(b)

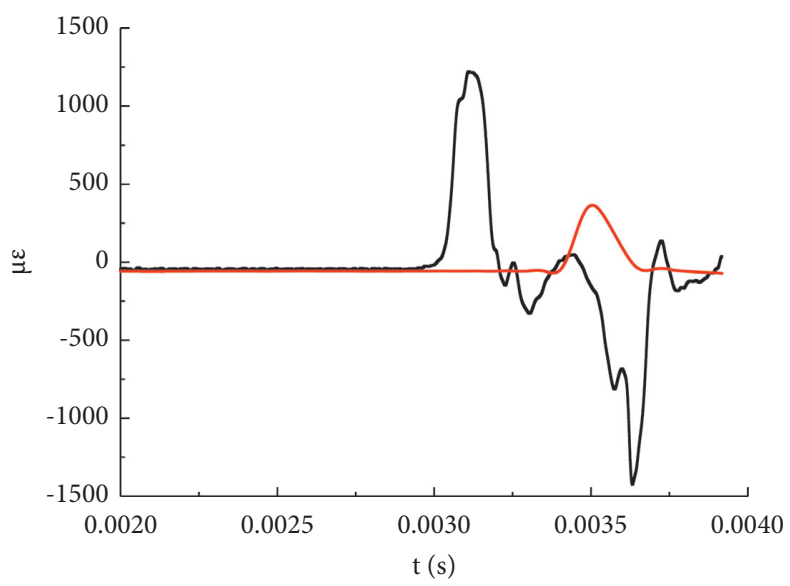

(d)

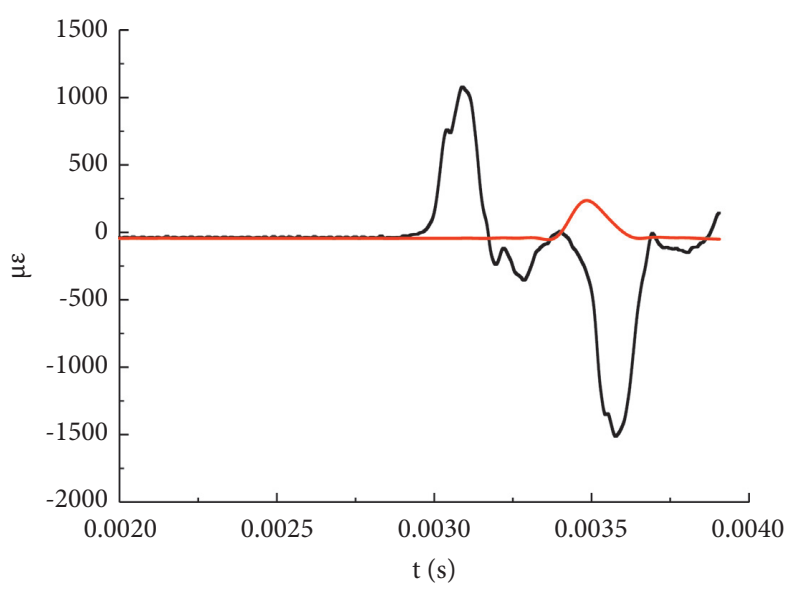

(f)

FiguRE 6: Strain curves of incident and transmissive bars at different moisture contents: (a) 6.63\%, (b) $9.22 \%$, (c) $11.91 \%$, (d) $15.37 \%$, (e) 18.65 , and (f) $21.73 \%$.

increasing moisture content, the specimen changes from crack failure to plastic deformation, and the higher the moisture content is, the larger the deformation. This shows that, with increasing moisture content, the larger the plastic deformation is, the greater the absorbed energy.
Analysis of the constitutive curve of the argillaceous weak cemented rock mass under dynamic loading.

The results show that increasing the rate of loading or changing the shape of the specimen does not change the basic model of rock failure, but it does increase the elastic modulus under dynamic loading. 


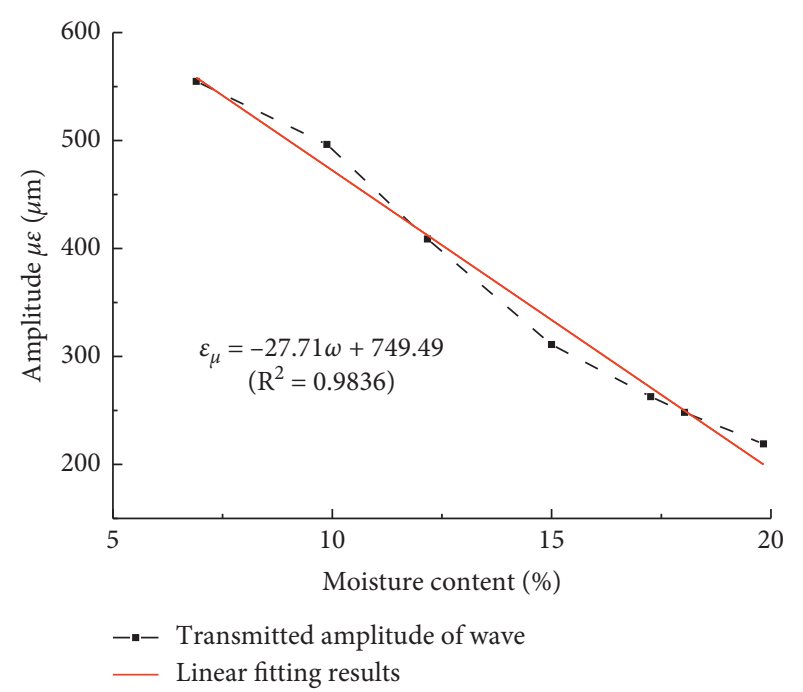

FIgURE 7: Transmission wave amplitude under different moisture contents.

It can be seen from Figures 8 and 9 that, under the same strain rate, the elastic modulus and peak strength of argillaceous weakly consolidated rock specimens decrease with increasing moisture content. When the moisture content is $6.63 \%$, the peak stress is $95.0 \mathrm{MPa}$. When the moisture contents are $6.63 \%, 9.22 \%, 11.91 \%, 15.37 \%, 18.65 \%$, and $21.73 \%$, the corresponding stress peaks are $80.79 \mathrm{MPa}$, $76.05 \mathrm{MPa}, \quad 55.52 \mathrm{MPa}, \quad 17.53 \mathrm{MPa}$, and $7.25 \mathrm{MPa}$, respectively.

When the moisture content is less than $10 \%$, the argillaceous weakly consolidated rock has the properties of soft rock, and a yield platform appears near the peak stress. With increasing strain, there is an obvious drop in stress, which shows that, under the condition of dynamic impact, the internal cementation structure at a low moisture content is destroyed, and the bearing capacity is obviously reduced. When the moisture content is between $10 \%$ and $15 \%$, the yield plateau appears at the peak stress. However, with increasing strain, there is no obvious drop in stress, and a yield platform less than the stress peak appears after the stress peak, which is similar to the ideal plastic deformation. When the moisture content is greater than $15 \%$, the peak value of the curve stress decreases obviously. However, after the peak value of the curve, there is no stress drop. Instead, the peak value of stress directly enters the plastic platform. This shows that the argillaceous weakly consolidated rock mass has good plasticity under the condition of a high moisture content. In the case of dynamic impact, there is plastic deformation, and its internal structure cementation has not been damaged.

A large number of SHPB test results show that the rock is destroyed by the tensile stress at the crack tip, and the failure process can be attributed to the rapid propagation of airfoil cracks. Under high strain rate loading, the crack growth rate is faster, and the free water in the sample will produce resistance to dynamic crack growth due to its surface tension and Stefan effect. During dynamic crack propagation, the free water cannot reach the crack tip, and the back of the crack tip is full of free water. Due to the surface tension of

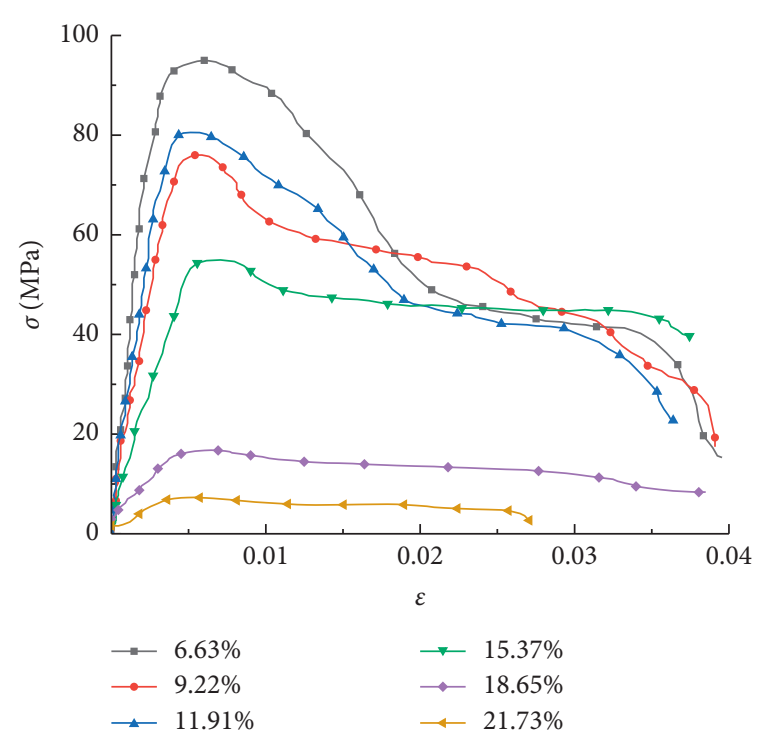

FIGURE 8: Stress-strain curves of argillaceous weakly consolidated rock with different moisture contents.

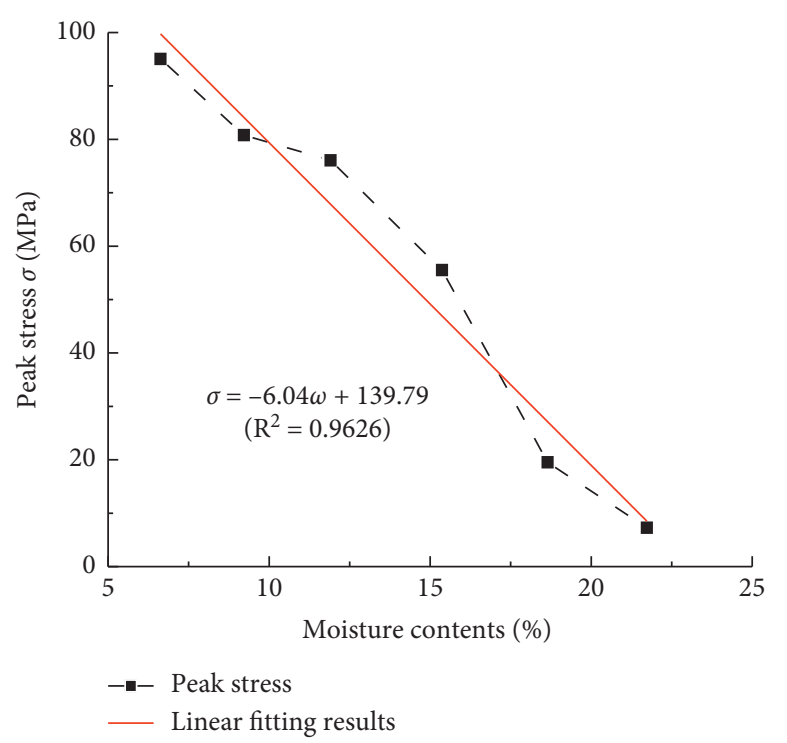

FIGURE 9: Peak stress-moisture content curves of argillaceous weakly consolidated rock.

water [46], the resistance $F_{3}$ which hinders the crack growth will be produced:

$$
F_{3}=\frac{V \gamma}{2 \delta^{2} \operatorname{COS} \psi}
$$

where $\mathrm{V}$ is the liquid volume, $\gamma$ is the surface energy, $\psi$ is the wetting angle, and $\delta$ is the radius of the water meniscus.

At the same time, the Stefan effect of free water in the crack surface of water-bearing sandstone will produce the resistance $F_{4}$ which hinders the relative separation of the two crack surfaces:

$$
F_{4}=\frac{3 \eta r^{2}}{2 \pi h^{3}} \frac{\mathrm{d} v}{\mathrm{~d} t}
$$




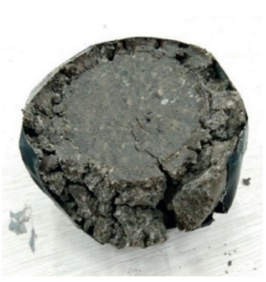

(a)

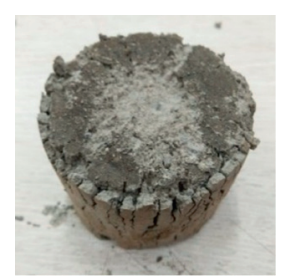

(b)

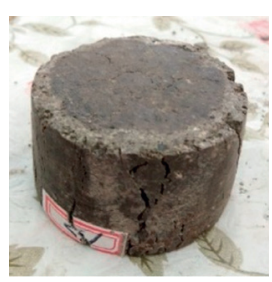

(c)

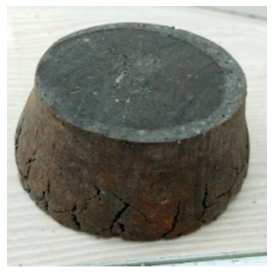

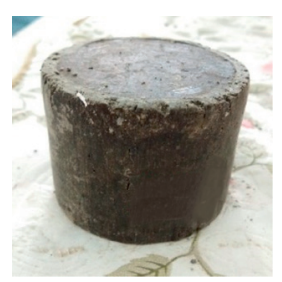

(d)

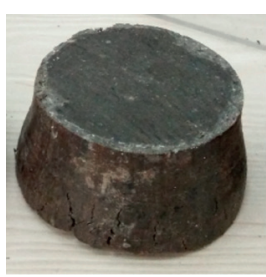

(e)

(f)

FIGURE 10: Specimens after impact with different moisture contents: (a) 6.63\%, (b) 9.22\%, (c) 11.91\%, (d) 15.37\%, (e) 18.65\%, and (f) $21.73 \%$.

where $\eta$ is the viscosity of the liquid, $r$ is the radius of the crack surface, $h$ is the distance between the two crack surfaces, and $v$ is the relative velocity of the separation of the two crack surfaces.

Under the condition of high strain rate loading, the dynamic crack propagation speed is faster, and the surface tension effect of free water and Stefan effect in airfoil crack will produce resistance to crack propagation. The larger the water content of argillaceous weakly cemented specimen is, the higher the degree of free water intrusion into the rock specimen is, the more the number of water-containing cracks in the specimen is, the greater the dynamic propagation resistance of cracks is, and the higher the dynamic uniaxial compressive strength is measured.

3.1.2. Analysis of the Morphology and Characteristics of Argillaceous Weakly Consolidated Rock Specimens. The study of the shape characteristics of the argillaceous weakly consolidated rock specimens after impact can deepen the understanding of its impact process and yield further understanding of the dynamic mechanical characteristics of the influences of moisture content. Figure 10 shows the specimens with different moisture contents after dynamic impact. This section analyses the height and diameter of the argillaceous weakly consolidated rock specimens after impact.

After SHPB test, the moisture content of the Group 1 of specimens was tested by drying method. The results are shown in Table 2.

It can be seen from Table 2 that the moisture content of argillaceous weakly consolidated rock is different, and its shape also exhibits a great difference after dynamic impact. The moisture content is a sensitive factor affecting the properties of argillaceous weakly consolidated rock.

According to Figure 11, when the moisture content of argillaceous weakly consolidated rock is less than $10 \%$, the diameter of the sample decreases with increasing moisture content after dynamic impact, and the height of the sample increases with increasing moisture content. The states of the specimens are broken and relatively broken. This is because when the moisture content is low, it has great hardness, but it is relatively brittle.

When the moisture content is $6.9 \%$, the specimen is broken by impact after dynamic impact, which is similar to the dynamic impact failure of rock. When the moisture content increases, the plasticity increases. When the moisture content is $9.88 \%$, the breaking degree of the specimens decreases obviously, and the shape of the sample deforms greatly. When the moisture content is greater than $12 \%$, the diameter of the specimen increases with increasing moisture content, and the height of the specimen decreases with increasing moisture content. The results show that, with increasing moisture content, the plasticity of the specimen increases, and the higher the moisture content is, the easier it is for plastic deformation to occur.

A large number of impact compression tests show that the rock is destroyed under the action of tensile stress at the crack tip. Under the condition of high strain rate loading, the crack dynamic propagation speed is fast, and the free water in the water-bearing specimen has no time to expand into the expansion crack. The wing crack not filled with water will be affected by the surface tension of free water in the specimen, which will produce the bonding force that will hinder the crack propagation, improving its dynamic strength.

\subsubsection{Microstructure Properties Analysis of Argillaceous} Weakly Consolidated Rock. After the SHPB test, the specimens of the G2 are submitted to the testing company for the mercury injection test. The moisture content of the specimens is shown in Table 3.

The porosity of argillaceous weakly consolidated rock after dynamic impact under different moisture content conditions is recorded in Figure 12, and the porosity of the weakly cemented rock mass after dynamic impact under different impact pressure conditions is shown in Figure 13.

When the moisture content of an argillaceous weakly consolidated rock specimen is less than $9.19 \%$, more cracks will appear in the specimen after impact, which is not 
TABLE 2: Speciation change parameters of specimens with different moisture contents.

\begin{tabular}{cccccc}
\hline Group & Number & Moisture content (\%) & Diameter $(\mathrm{mm})$ & Height $(\mathrm{mm})$ & Status description \\
\hline & $\mathrm{S}_{1}$ & 6.63 & 60.2 & 37.1 & Broken \\
& $\mathrm{S}_{4}$ & 9.22 & 57.4 & 40.8 & Relatively broken \\
G1 & $\mathrm{S}_{7}$ & 11.91 & 56.2 & 42.3 & Slightly broken \\
& $\mathrm{S}_{10}$ & 15.37 & 58.1 & 40.2 & Relatively complete \\
& $\mathrm{S}_{13}$ & 18.65 & 61.7 & 32.5 & Slight crack \\
& $\mathrm{S}_{16}$ & 21.73 & 64.4 & 28.6 & Large crack \\
\hline
\end{tabular}

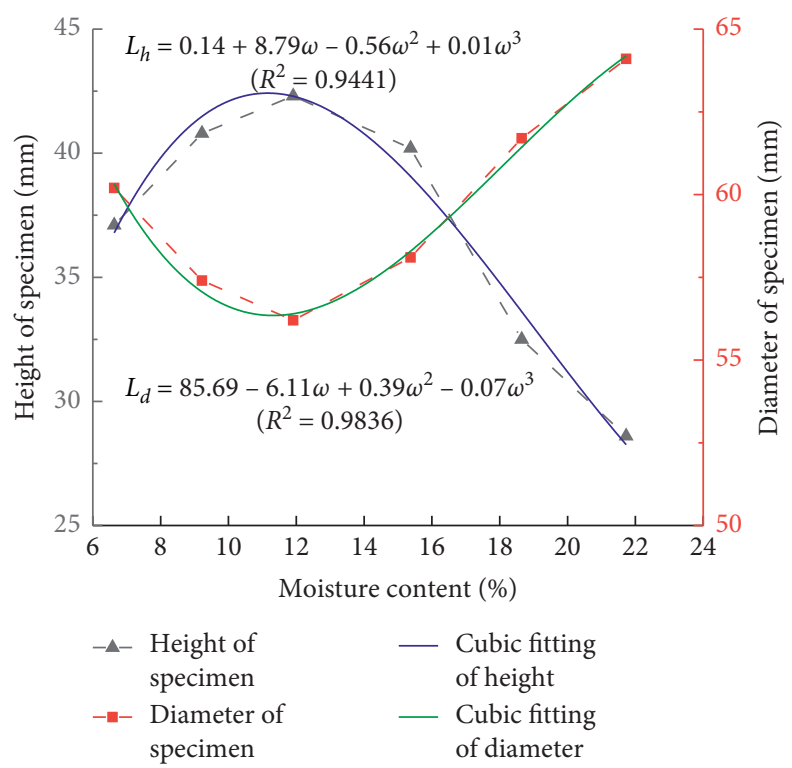

FIGURE 11: Dynamic impact specimen size change curves with different moisture contents.

TABle 3: Moisture content of G2 of specimens.

\begin{tabular}{lcccccc}
\hline Number & $\mathrm{S}_{2}$ & $\mathrm{~S}_{5}$ & $\mathrm{~S}_{8}$ & $\mathrm{~S}_{11}$ & $\mathrm{~S}_{14}$ & $\mathrm{~S}_{17}$ \\
\hline Moisture content (\%) & 6.58 & 9.19 & 11.77 & 15.21 & 18.43 & 21.02 \\
\hline
\end{tabular}

suitable for the mercury injection test. The porosity of argillaceous weakly consolidated rock decreases with increasing moisture content after the same dynamic impact, and the change rate of porosity also decreases gradually. The porosity curve can be roughly divided into two sections. In the first section, the change rate of porosity is greatly impacted by dynamic loading. When the moisture content is less than $15 \%$, the porosity changes greatly with increasing moisture content. When the moisture content increases from $9.19 \%$ to $11.77 \%$, the porosity of the specimen decreases by $10.82 \%$. When the moisture content increases from $11.77 \%$ to $15.21 \%$, the porosity of the specimen decreases by $3.62 \%$. At this stage, the value of porosity is high, which indicates that, after dynamic impact, new cracks are produced in the structure of the specimens. The reason is that, under the condition of low moisture content, the plasticity of the specimen is relatively low, and the specimen is mainly brittle after dynamic impact, so the porosity changes obviously with increasing moisture content. In the second stage, when the moisture content is greater than $15 \%$, the porosity changes less with increasing moisture content. When the moisture content is $18.43 \%$, the porosity of argillaceous weakly cemented rock mass is $22.84 \%$; when the moisture content is $21.02 \%$, the porosity of the specimen is $22.71 \%$. When the moisture content increases from $15.21 \%$ to $18.43 \%$, the porosity of the specimen decreases by $0.18 \%$. When the moisture content increases from $18.43 \%$ to $21.02 \%$, the porosity of the specimen decreases by $0.57 \%$. When the moisture content is greater than $15 \%$, the argillaceous weakly consolidated rock has strong plasticity, and the dynamic impact of the specimens produces plastic deformation, so the porosity changes little with increasing moisture content.

There are closed and open pores in the sample, and water can only enter the open pores. When the water content is low, the mudstone particles expand, and the indirect contact of particles shows compressive stress. At high moisture content, the particles cool and contract, and the compressive stress at the contact between particles becomes tensile stress. It leads to microcracks at the contact of rock particles, or 


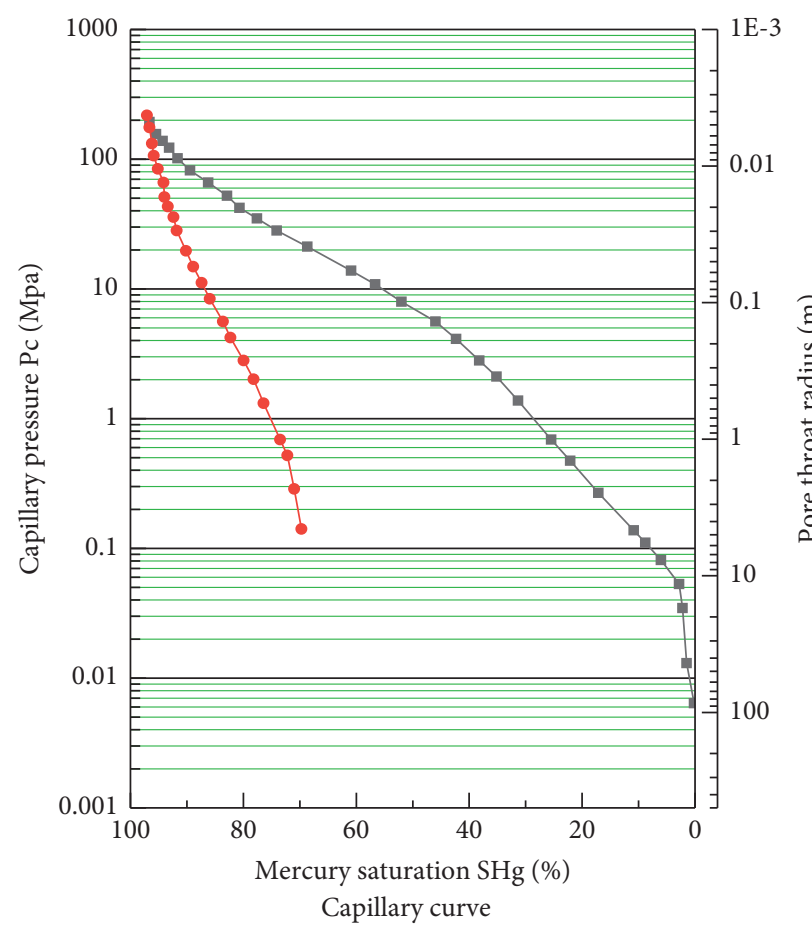

$\rightarrow-$ Mercury injection

$\rightarrow$ Mercury regression

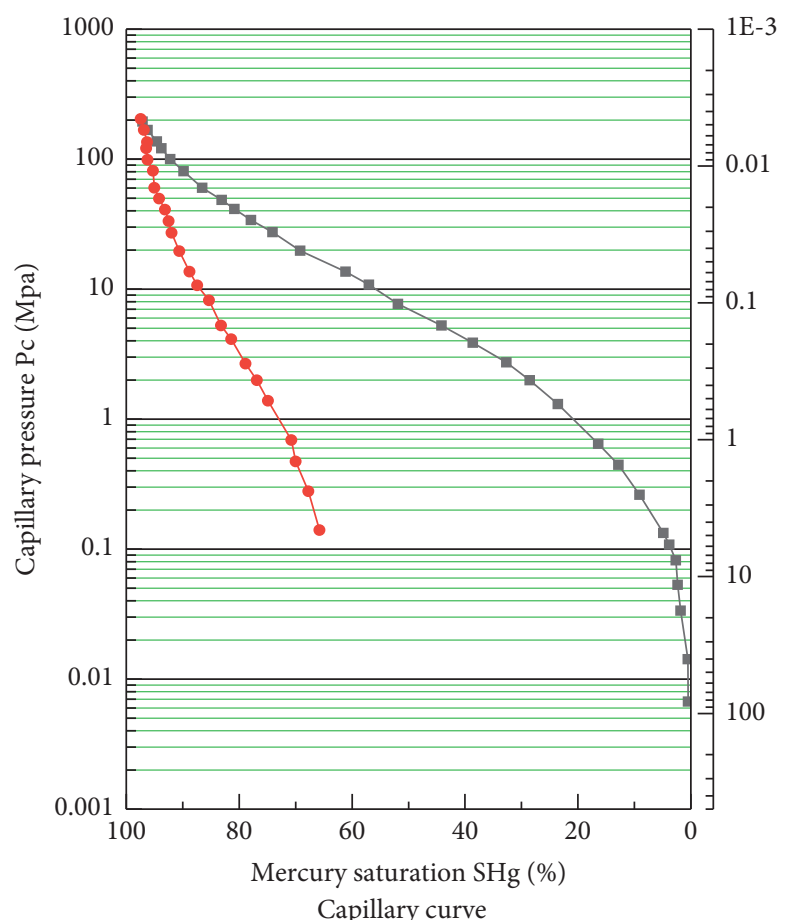

Capillary curve

- Mercury injection

- Mercury regression
Displacement pressure $(\mathrm{MPa}): 0.055$

Median pore throat radius (um) : 0.104

Median mercury saturation (MPa) : 7.359

Maximum mercury saturation (\%) : 96.613

Permeability distribution peak (\%) : 54.141

Peak value of pore distribution (\%) : 8.837

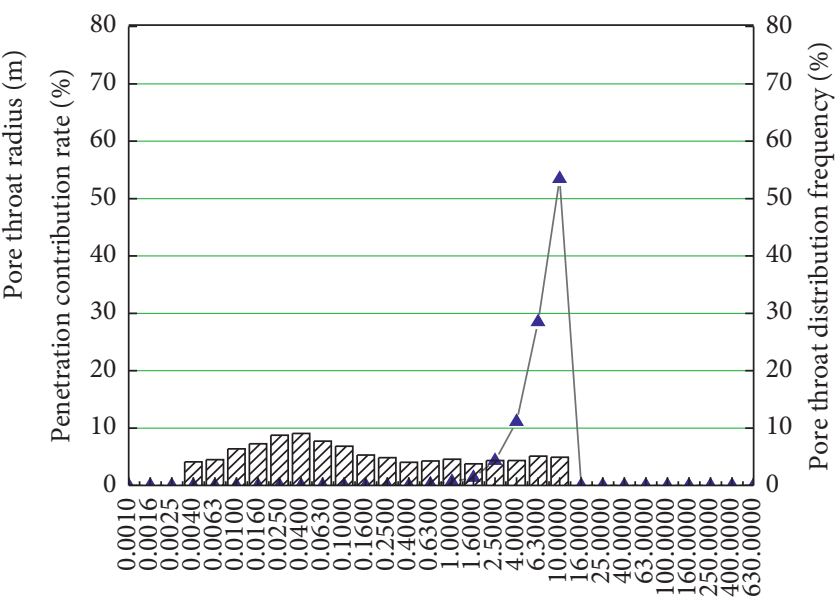

Distribution of voids (um)

Pore throat distribution

¿- Penetration contribution rate

VIIA Pore throat distribution frequency

(a)

Displacement pressure (MPa) : 0.138

Median pore throat radius (um) : 0.098

Median mercury saturation (MPa) : 7.737

Maximum mercury saturation (\%) : 96.840

Permeability distribution peak (\%) : 55.805

Peak value of pore distribution (\%) : 8.938

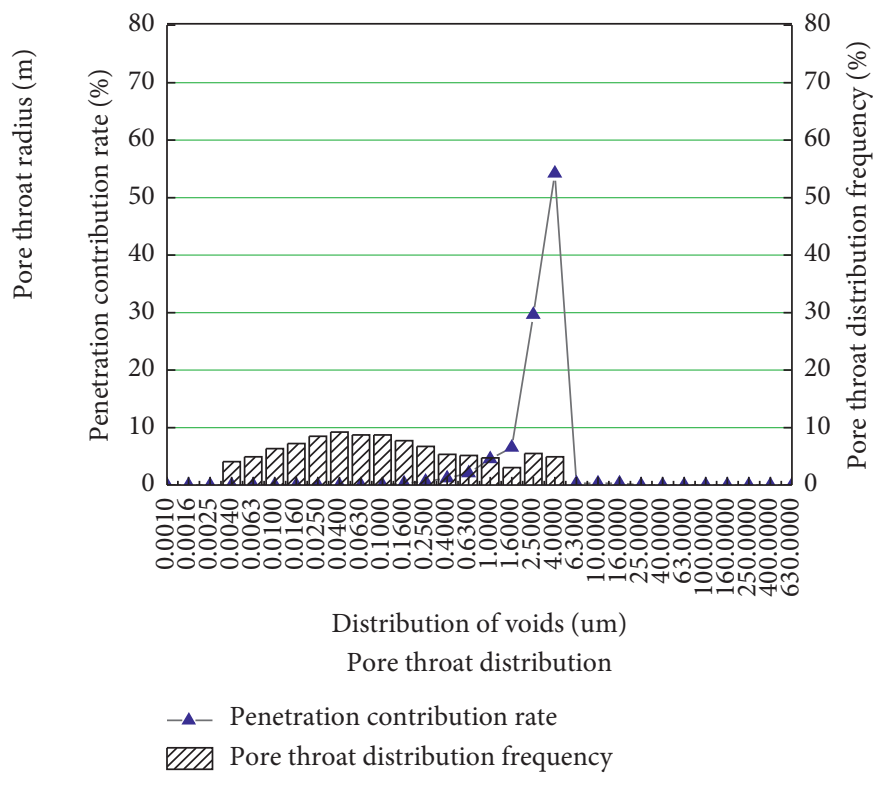

(b)

FIgURE 12: Continued. 


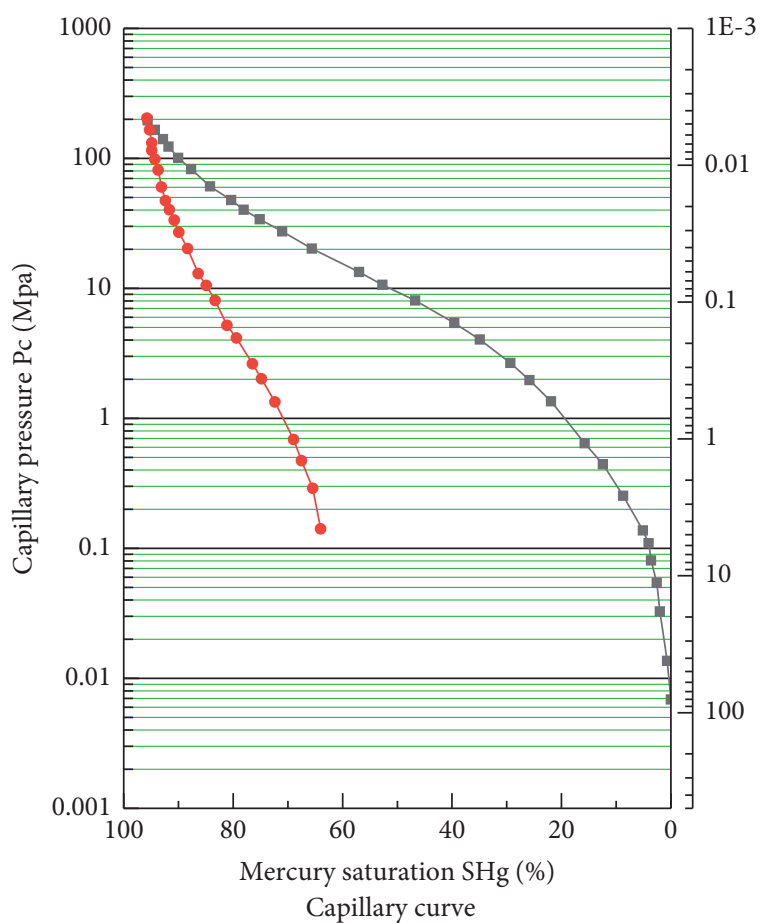

$\rightarrow$ Mercury injection

$\rightarrow$ Mercury regression

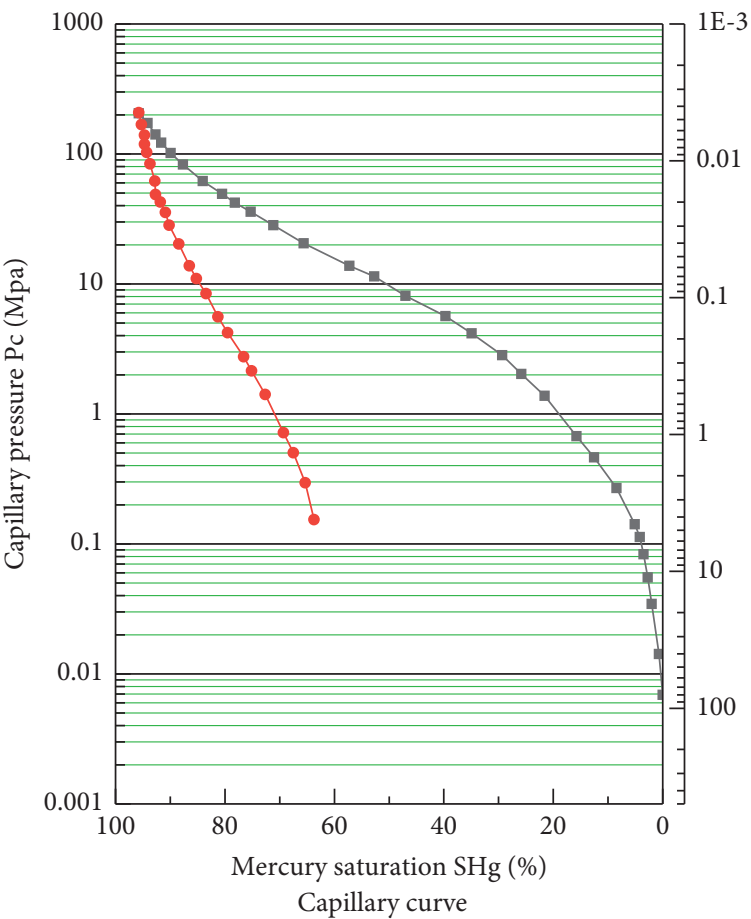

$\rightarrow$ Mercury injection

$\rightarrow$ Mercury regression
Displacement pressure (MPa) : 0.296

Median pore throat radius (um) : 0.079

Median mercury saturation (MPa) : 9.750

Maximum mercury saturation (\%) : 95.456

Permeability distribution peak (\%) : 54.831

Peak value of pore distribution (\%) : 9.500

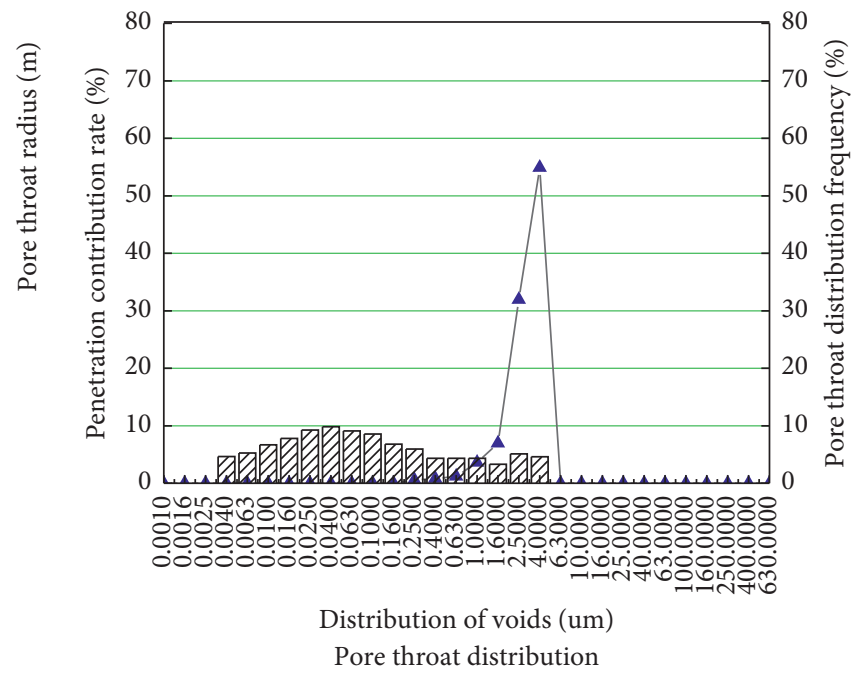

- - - Penetration contribution rate

WIA Pore throat distribution frequency

(c)

Displacement pressure (MPa) : 0.453

Median pore throat radius (um) : 0.077

Median mercury saturation (MPa) : 9.764

Maximum mercury saturation (\%) : 95.476

Permeability distribution peak (\%) : 54.946

Peak value of pore distribution (\%) : 9.983

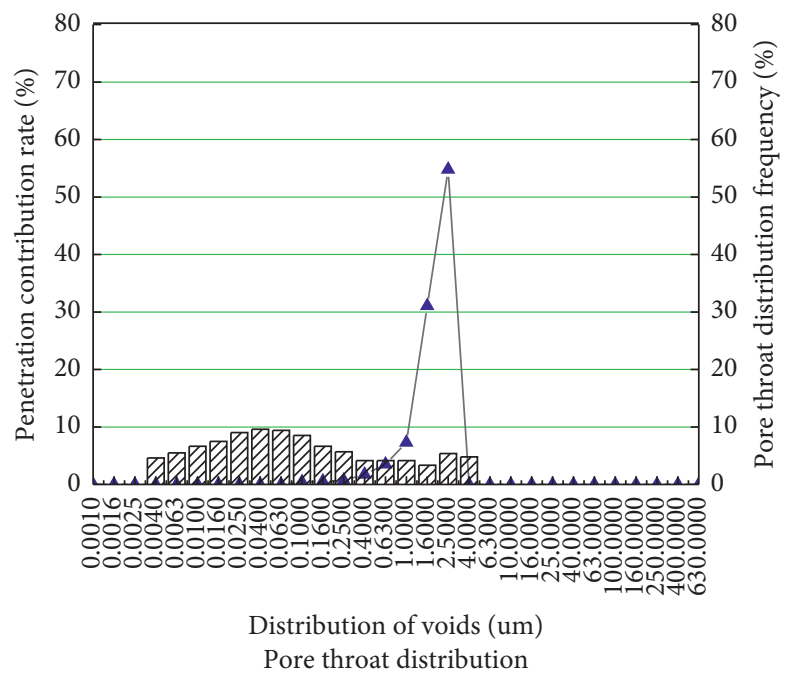

\- Penetration contribution rate

VIIA Pore throat distribution frequency

(d)

Figure 12: Continued. 

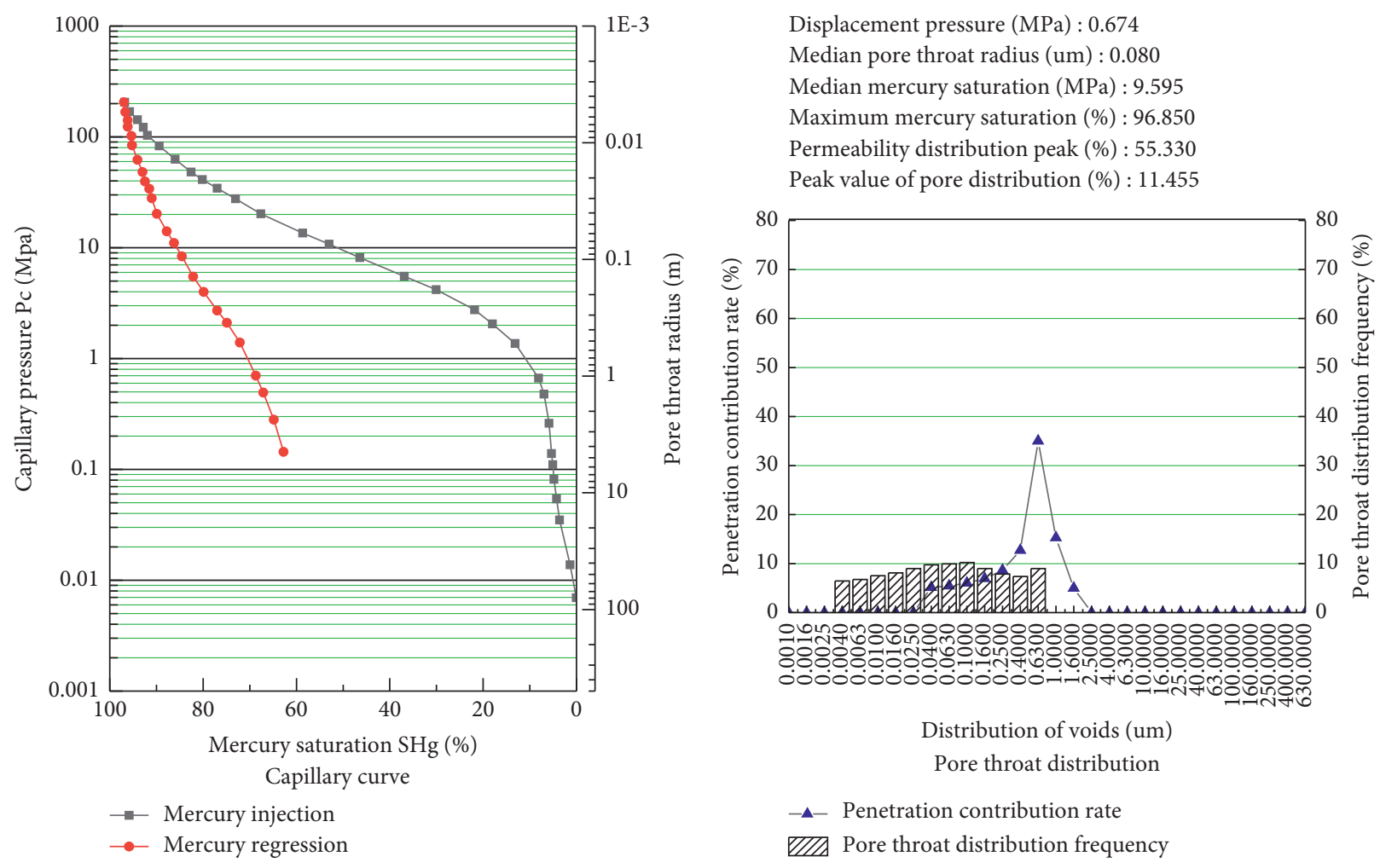

(e)

Figure 12: Mercury injection test data map of argillaceous weakly consolidated rock under different moisture content conditions: (a) 9.19\%, (b) $11.77 \%$, (c) $15.21 \%$, (d) $18.43 \%$, and (e) $21.02 \%$.

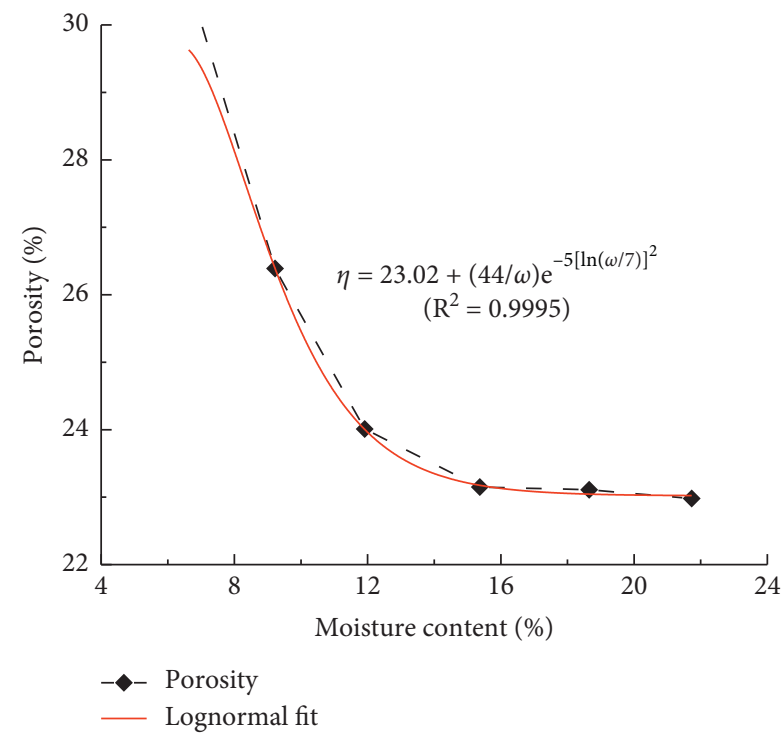

FIGURE 13: Porosity of argillaceous weakly consolidated rock under different moisture content conditions.

closed pores open into open pores, so that water can enter deeper areas in the sandstone specimen. The rock particles eroded by water gradually increase, and the microcracks between particles increase, weakening the adhesion between rock particles, thus reducing the strength of rock.
TABLE 4: Moisture content of G3 of specimens.

\begin{tabular}{lcccccc}
\hline Number & $\mathrm{S}_{3}$ & $\mathrm{~S}_{6}$ & $\mathrm{~S}_{9}$ & $\mathrm{~S}_{12}$ & $\mathrm{~S}_{15}$ & $\mathrm{~S}_{18}$ \\
\hline Moisture content (\%) & 6.66 & 9.18 & 11.87 & 15.19 & 18.69 & 21.77
\end{tabular}

3.1.4. Macroscopic Properties Analysis of Argillaceous Weakly Consolidated Rock. After SHPB, MTS-816 was used for the uniaxial compression test of the G3 of specimens. The moisture content was tested after the test and the results are shown in Table 4.

Due to the size limitation of the SHPB specimen, the diameter to height ratio of the SHPB specimen is $1: 1$. It is difficult to make the specimen with the ratio of height to diameter of $2: 1$ according to the test procedure after dynamic load impact. Although the following uniaxial compression test can not accurately reflect the compressive strength of rock, it can reveal part of the mechanical properties of rock after dynamic load impact from another point of view. Therefore, the strength described in this chapter is not the uniaxial compressive strength in the standard sense. The relationship between the data of mechanical properties obtained in this test and the real compressive strength needs to be further studied.

In this section, the mechanical properties of uniaxial compression of argillaceous weakly cemented rock mass after dynamic impact are studied, and the influence of moisture content on the structural strength of argillaceous 
weakly cemented rock mass under dynamic impact is preliminarily revealed. The stress-strain curve of the uniaxial test for different moisture contents of argillaceous weakly consolidated rock specimen mass is shown in Figure 14.

It can be seen from Figure 14 that the mechanical properties of argillaceous weakly consolidated rock specimens are quite different after dynamic impact under different moisture contents. According to the literature, argillaceous weakly consolidated rock has the properties of soft rock and hard soil. When the moisture content of a specimen is high, it has the properties of soft rock with low strength, high plasticity, and large deformation. When the moisture content is low, the specimen has the properties of hard soil with high strength, high brittleness, and low plasticity, and the specimen can easily be damaged after dynamic impact. In the dynamic impact test, the specimen with a moisture content of $6.63 \%$ is damaged, and its peak strength and residual strength are very low. With increasing moisture content, the peak value and residual stress of the specimen increase. When the moisture content is greater than $15 \%$, with increasing moisture content, the plasticity of the specimen increases, and the peak stress and residual stress decrease.

Compared with the dry state, there is free water in the microcracks of mudstone with high water content. The water absorption process of mudstone is a process in which free water continuously invades the interior of the specimen from the outer surface of the specimen. The greater the moisture content of the specimen, the higher the degree of free water intrusion into the rock specimen and the more the water-containing cracks.

Under the condition of high strain rate loading, the crack dynamic propagation speed is fast, and the surface tension of free water and Stefan effect in the airfoil crack will produce resistance to crack propagation. The greater the moisture content of the specimen, the greater the dynamic crack propagation resistance.

It can be seen from Figure 15 that the peak strength and residual stress of argillaceous weakly consolidated rock after dynamic impact can be divided into two stages with increasing moisture content, with a boundary of $15.19 \%$. In the process of the moisture content increasing from $6.66 \%$ to $15.19 \%$, the peak strength increases from $0.356 \mathrm{MPa}$ to $1.299 \mathrm{MPa}$ with a growth rate of $264.89 \%$, and the residual strength increases from $0.301 \mathrm{MPa}$ to $1.200 \mathrm{MPa}$ with a growth rate of $298.67 \%$ after impact. When the moisture contents are $6.66 \%, 9.18 \%, 11.87$, and 15.19 , the peak strength growth rates are $103.37 \%, 52.90 \%$, and $17.34 \%$, respectively, and the residual strength growth rates are $69.77 \%, 56.56 \%$, and $50.00 \%$, respectively. When the moisture content is greater than $15.19 \%$, the peak strength and residual stress decrease with increasing moisture content. When the moisture content increases by $15.19 \%$, $18.69 \%$, and $21.77 \%$, the peak strength reduction rate is between $34.96 \%$ and $19.36 \%$, and the residual strength reduction rate is between $30.33 \%$ and $19.26 \%$, respectively.

When the moisture content is less than $10 \%$, the plasticity of argillaceous weakly consolidated rock is low. After dynamic impact, the specimen is relatively broken, its

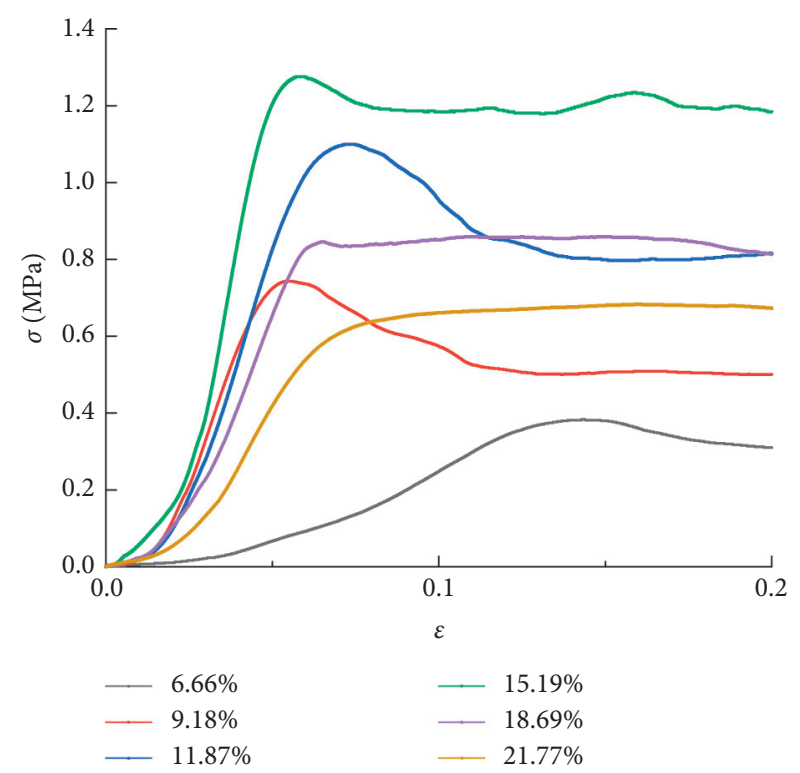

FIGURE 14: Full stress-strain curve of specimens under uniaxial test with different moisture contents.

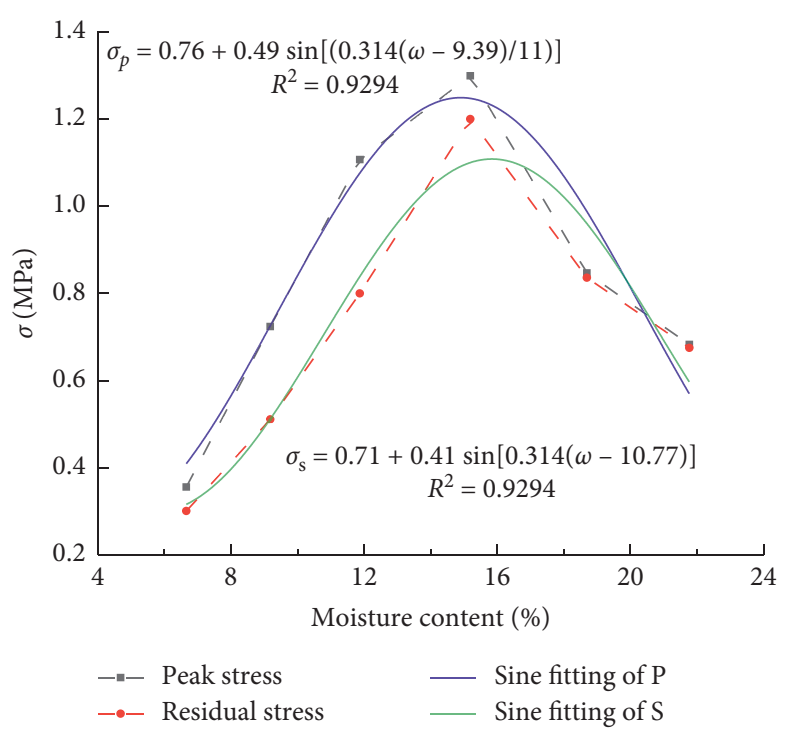

FIgURE 15: The peak stress and residual stress curves with different moisture contents.

bearing capacity is very low, and its peak stress and residual stress are almost equal. That is, in the process of uniaxial compression, because the specimen is relatively broken, the stress curve goes directly from the compaction stage to the residual stage. With increasing moisture content, the plasticity of the argillaceous weakly consolidated rock specimen increases. When the moisture content is $9.18 \%$, the peak strain-softening stage appears in the stress-strain curve, and it begins to have the properties of soft rock. When the moisture content is $11.87 \%$, the peak values of uniaxial compression stress and residual stress will increase after dynamic impact, which shows that the internal structure of the specimen will be damaged first and then reorganized 
after dynamic impact, and the difference between the residual stress and peak stress is the largest, with a value of 3.07 MPa. When the moisture content is $15.19 \%$, the peak stress and residual stress of the specimen are the maximum, the difference between the residual stress and the peak stress is reduced, the softening stage of argillaceous weakly consolidated rock mass is shortened, it enters the residual stage, and the deformation in the residual stage is close to ideal plastic deformation. When the moisture content is $18.69 \%$, the plasticity of the specimen increases, the peak stress and residual stress decrease, the difference between the peak stress and residual stress further decreases, and the plasticity of the specimen further increases. There is no strain-softening stage in the stress-strain curve, and then an ideal plastic platform appears. The residual stress value is basically consistent with the peak stress. When the moisture content is $21.77 \%$, the peak value of stress continues to decrease. After the dynamic impact, the axial deformation of the specimen is larger. When the uniaxial compression is performed, the stress-strain curve directly enters the ideal plastic deformation platform.

It can be seen from Figure 16 that when the moisture content of an argillaceous weakly consolidated rock specimen is less than $15.19 \%$, its elastic modulus increases with increasing moisture content. When the moisture content of the specimen is more than $15.19 \%$, its elastic modulus decreases with increasing moisture content. When the moisture content is $6.66 \%$, the specimen exhibits a certain brittleness, and it is broken after being impacted by dynamic force, with the minimum elastic modulus. When the moisture content increases to $9.18 \%$, the plasticity of the specimen increases. After the dynamic impact, the porosity decreases, and the particle structure inside the specimen is squeezed and cemented again. Because the moisture content is relatively low, the particles inside the specimen are only partially cemented again, and the cementation between some original particles is destroyed. When the moisture content is increased to $11.87 \%$, the plasticity of the specimen is further enhanced. After the dynamic impact, the porosity of the specimen decreases. Because of increasing plasticity, its internal particle structure is also squeezed, the proportion of particles recemented in the internal structure of the specimen increases, the internal structure is strengthened, and the strength of the specimen is revealed. When the moisture content reaches $15.19 \%$, the plasticity of the specimen continues to increase. After the dynamic impact, the porosity further decreases, the internal structure of the sample is compacted, the proportion of the reorganization particles in the internal structure of the sample reaches the maximum, and the strength is improved. When the moisture content is greater than $15 \%$, the argillaceous weak cemented rock mass is easy to deform, and its strength is reduced. When the moisture content reaches $18.69 \%$, the elastic modulus of the weak cemented argillaceous rock sample is further reduced after impact, and the softening stage of the stress-strain curve is further shortened, directly entering the ideal plastic deformation stage. The results show that the decreasing trend of porosity is slowed down after the dynamic impact of argillaceous weak cemented rock mass at a

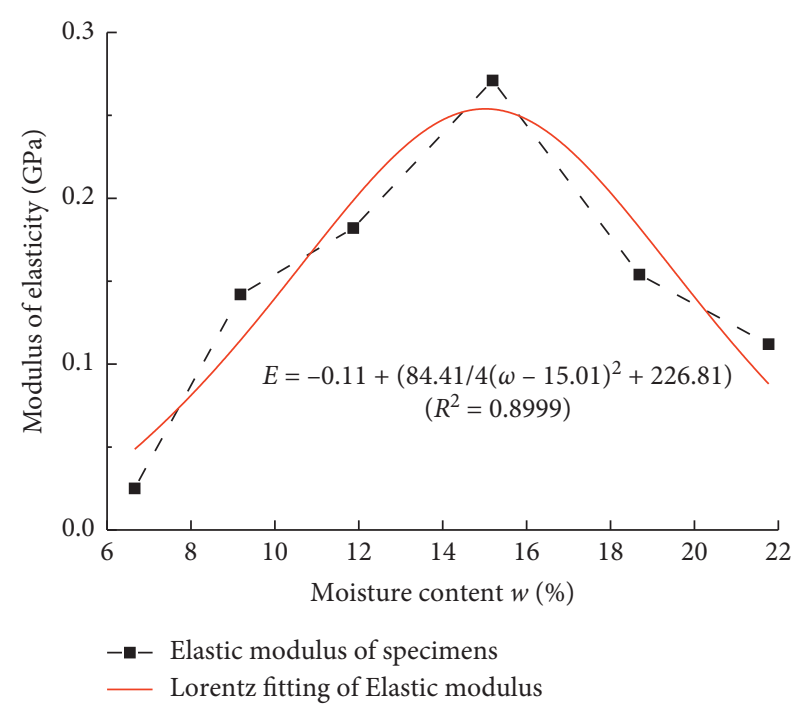

FIGURE 16: Modulus of elastic of specimens with different moisture contents.

high moisture content. The main deformation of the sample is plastic deformation. Its compressive strength decreases with increasing moisture content, and its elastic modulus also decreases. The modulus of elasticity decreases with increasing moisture content.

\section{Discussion}

4.1. Effects of Mineral Composition and Microstructure on Properties of the Rock. The argillaceous weakly cemented rock mass has the characteristics of soft rock and hard soil. The rock mass can easily lose water and be weathered in a dry environment, and it can easily absorb water and disintegrate in a humid environment. When the argillaceous weakly cemented rock mass has a low moisture content, its lithology exhibits brittleness and has a certain hardness [25, 47, 48]. When it has a high water content, the rock mass has the characteristics of plastic soil. In this paper, because the specimens are taken from the same place, it can be assumed that the mineral composition and crystal structure are the same. On this basis, the influence of water moisture on mudstone is discussed. The influence of moisture content on mineral composition and crystal structure will also be the focus of future work.

According to the XRD data, the argillaceous weakly cemented rock mass contains a large number of clay minerals, such as kaolinite, illite, and illite-montmorillonite mixed layers. The weakly cemented mudstone is composed of quartz, feldspar, and other clastic minerals, which form the basic skeleton structure, while the clay minerals, such as kaolinite, illite, and illite-montmorillonite, are mainly cemented. The filling of clay minerals is not dense, and there will be a honeycomb in a loose structure. The microvoids are relatively developed, and microcracks connect these microdefects, forming a good channel for water to enter the mineral interior. Kaolinite is water-absorbent and plastic when it meets water, and montmorillonite expands when it 
meets water. Among them, montmorillonite and illite/ montmorillonite are mixed minerals with a strong water absorption capacity, which causes the rock body to have strong water sensitivity and expansibility. Water molecules enter between the crystal cells and the particles, forming interlayer expansion and interparticle expansion. Increasing water content can destroy the interaction between some particles in mudstone and separate clay minerals from nonexpansive minerals. The separated clay minerals adsorb water molecules on their surface and cause overall volume expansion and rock softening, resulting in the structural damage of weakly cemented rock.

\subsection{Full Stress-Strain Curve of the Rock under Dynamic Load.} Although the following uniaxial compression test cannot accurately reflect the compressive strength of rock, it can reveal part of the mechanical properties of rock after dynamic load impact from another point of view. The relationship between the data of mechanical properties obtained in this test and the real compressive strength needs to be further studied. A method similar to the stress-strain curve in the static compression test is used to divide into the following four stages.

Firstly, the compaction stage: at this stage, the stressstrain curve shows concave variation. We can infer two main reasons for this feature. At the beginning of the test, there is a certain gap between the end face of the sample and the incident rod, and the gap disappears after the beginning of the test. The second reason is the closure of microcracks in the rock under load.

Secondly, the approximately linear elastic stage: at this stage, the stress-strain curve basically presents an approximate straight line. The external loads are not sufficient to make the crack grow and evolve or produce new cracks in the sample, only to make the deformation of the original crack stable or produce small amplitude changes. The elastic energy accumulates continuously, and the elastic deformation state of the sample does not change qualitatively. The slope of the curve basically remains unchanged.

Thirdly, the microcrack propagation stage: with the increase of stress, the increasing speed of strain slows down, and the curve is convex. With the increase of the applied force on the sample, the original cracks in the rock increase and new cracks appear. At this stage, plastic deformation becomes the dominant deformation. At the end of this stage, the stress value is the peak stress, and the corresponding strain value is the peak strain.

Fourthly, the strain-softening stage: with the increase of strain, the stress begins to decrease and tends to a stable value. After the peak stress appears, the bearing capacity of the specimen begins to decrease. The reason why the specimen can maintain stability at this stage is that the plastic deformation is dominant.

4.3. Influence of Energy on Characteristics of the Rock. For the comprehensive SHPB and uniaxial compression test, the total energy absorbed by mudstone slows down gradually with the growth rate of strain. The higher the water content is, the less the total energy absorbed by the mudstone. The reason is that water molecules can easily enter the clay mineral particles, such as illite and kaolinite, which weakens the cohesion between particles, and the dissolution of argillaceous cement and the water absorption and expansion of clay minerals destroy the structure of the mudstone, soften the rock, and reduce the mechanical properties.

4.4. Relationship between Energy Dissipation and Damage Degree. When the sample is broken into blocks, the dissipated energy per unit volume is less, and when the core is broken, the dissipated energy increases accordingly. This is mainly because the energy obtained by the sample will be released in the form of generation and development of microcracks in the material after the sample is impacted by the compression bar system. Therefore, the number and development of microcracks are related to the energy dissipation per unit volume. When the energy dissipation per unit volume is large, the formation of a large number of microcracks directly leads to the crushing failure of materials. When the dissipation energy per unit volume is very low, the number of microcracks is relatively reduced and the failure particles are large. However, there is no one-to-one correspondence between the failure degree of the sample and the strain rate. At a low strain rate, it will also show crushing failure, while at a high strain rate, it will break into blocks.

Some researchers use the fractal dimension to quantitatively characterize the damage degree of rock. According to the measurement of mass frequency relationship, the distribution equation of rock impact fragmentation can be obtained, and then the fractal dimension of fragmentation can be obtained. The larger the fractal dimension is, the more the fragments are, and the smaller the size is, the more serious the fragmentation degree is. In this paper, fractal dimension is not used to quantitatively characterize the failure degree of mudstone samples.

\section{Conclusions}

In this paper, through SHPB, mercury injection, and uniaxial compression tests, the structural and mechanical characteristics of argillaceous weakly consolidated rock mass under dynamic impact are analysed, and the following conclusions are drawn:

(1) In this paper, the dynamic impact uniaxial test is carried out on specimens of argillaceous weakly consolidated rock by using the separate Hopkinson compression bar device. With increasing moisture content, the elastic modulus and peak stress of the argillaceous weakly consolidated rock decrease. When the moisture content is less than $10 \%$, the specimen exhibits a certain brittleness, and the stress curve has a steep drop in the residual stage. When the moisture content is approximately $15 \%$, the residual stress is the maximum. When the moisture content is greater than $15 \%$, the peak stress and residual stress of the specimen decrease sharply. 
(2) The analysis of the shape of the specimen after impact shows that when the moisture content is less than $10 \%$, the specimen has obvious crack damage after impact. When the moisture content is greater than $10 \%$, the plastic deformation of the specimen increases with increasing the moisture content.

(3) The dynamic stress-strain curve of the argillaceous weakly consolidated rock mass can be divided into four stages: the compaction stage, approximate linear elastic stage, microcrack propagation stage, and strain-softening stage.

(4) When the moisture content of an argillaceous weakly consolidated rock specimen is less than $10 \%$, there are many cracks in the specimen after impact, and they are connected with each other, so it is not suitable for the mercury injection test. When the moisture content is greater than $10 \%$ and less than $15 \%$, the porosity decreases obviously after dynamic impact, which indicates that the specimen is easy to squeeze and compress. When the moisture content of a specimen is greater than $15 \%$, the porosity of the specimen is basically the same after being impacted.

(5) When the moisture content is lower than $9.18 \%$, the argillaceous weakly cemented rock specimen is destroyed by the dynamic impact, and its elastic modulus, peak stress, and residual strength are very small. When the moisture content is between $9.18 \%$ and $15.19 \%$, the modulus of elasticity, peak stress, and residual strength increase with increasing moisture content. When the moisture content is greater than $15.19 \%$, the elastic modulus, peak stress, and residual strength decrease with increasing moisture content. The results show that the optimum moisture content of the argillaceous weakly consolidated rock is approximately $15 \%$.

\section{Data Availability}

The data used to support the findings of this study are available from the corresponding author upon request.

\section{Conflicts of Interest}

The authors declare that there are no conflicts of interest regarding the publication of this paper.

\section{Acknowledgments}

The first author is grateful to all the coauthors for providing innovative ideas, the State Key Laboratory for GeoMechanics and Deep Underground Engineering, China University of Mining and Technology, for providing instruments to conduct the research, and Xiyi Coal Mine, subordinated by China Resources Power Holdings Company Limited, for providing geological data and rock cores. This study was supported by the National Natural Science Foundation of China (NSFC) (Grant nos. 51574223 and 51704280).

\section{References}

[1] D. Y. Cao, Z. Y. Lin, Z. H. Zheng, and J. Q. Tan, "Coalfield structures and potential evaluation of coal resources in China," Advanced Materials Research, vol. 356-360, pp. 2937-2940, 2011.

[2] M.-C. He, Z.-J. Fang, and P. Zhang, "Theoretical studies on the extrinsic defects of montmorillonite in soft rock," Modern Physics Letters B, vol. 23, no. 25, pp. 2933-2941, 2011.

[3] S. Göb, A. Loges, N. Nolde, M. Bau, D. E. Jacob, and G. Markl, "Major and trace element compositions (including REE) of mineral, thermal, mine and surface waters in SW Germany and implications for water-rock interaction," Applied Geochemistry, vol. 33, pp. 127-152, 2013.

[4] A. G. Corkum and C. D. Martin, "The mechanical behaviour of weak mudstone (opalinus clay) at low stresses," International Journal of Rock Mechanics and Mining Sciences, vol. 44, no. 2, pp. 196-209, 2007.

[5] D. T. Vaniman, D. L. Bish, and D. W Ming, "Mineralogy of a mudstone at yellowknife bay, gale crater, mars," Science, vol. 343, no. 6169, Article ID 1243480, 2014.

[6] J. Jiang and $\mathrm{J} . \mathrm{Xu}$, "Investigation of energy mechanism and acoustic emission characteristics of mudstone with different moisture contents," Shock and Vibration, vol. 2018, Article ID 2129639, 11 pages, 2018.

[7] D. Ma, X. Cai, Z. Zhou, and X. Li, "Experimental investigation on hydraulic properties of granular sandstone and mudstone mixtures," Geofluids, vol. 2018, Article ID 9216578, 13 pages, 2018.

[8] A. Daraei and S. Zare, "Effect of water content variations on critical and failure strains of rock," KSCE Journal of Civil Engineering, vol. 22, no. 9, pp. 3331-3339, 2018.

[9] B. Schwartz, K. Huffman, D. Thornton, and D. Elsworth, "The effects of mineral distribution, pore geometry, and pore density on permeability evolution in gas shales," Fuel, vol. 257, Article ID 116005, 2019.

[10] M. N. Bagde and V. Petroš, "The effect of machine behaviour and mechanical properties of intact sandstone under static and dynamic uniaxial cyclic loading," Rock Mechanics and Rock Engineering, vol. 38, no. 1, pp. 59-67, 2004.

[11] A. B. Hawkins and B. J. McConnell, "Sensitivity of sandstone strength and deformability to changes in moisture content," The Quarterly Journal of Engineering Geology and Hydrogeology, vol. 25, no. 2, pp. 115-130, 1992.

[12] B. Vásárhelyi and P. Ván, "Influence of water content on the strength of rock," Engineering Geology, vol. 84, no. 1-2, pp. 70-74, 2006.

[13] Z. A. Erguler and R. Ulusay, "Water-induced variations in mechanical properties of clay-bearing rocks," International Journal of Rock Mechanics and Mining Sciences, vol. 46, no. 2, pp. 355-370, 2009.

[14] Z.-P. Meng and X.-M. Xian, "Analysis of the mechanical property of mudstone/shale in paralic coal measures and its influence factors," Journal of Coal Science and Engineering, vol. 19, no. 1, pp. 1-7, 2013.

[15] H. X. Li, Y. W. Wang, and B. X. Tang, "Soft rock roadway mesh shell lining experimental study of the mechanical properties," Advanced Materials Research, vol. 671-674, pp. 774-777, 2013.

[16] S. Wang, L. Han, Q. Meng, Y. Jin, and W. Zhao, "Water absorption/dehydration by NMR and mechanical response for weakly cemented mudstones subjected to different humidity conditions," Bulletin of Engineering Geology and the Environment, vol. 79, no. 3, pp. 1275-1288, 2019. 
[17] V. A. Kovalenko and V. V. Grigor'ev, "Rock destruction by dynamic load," Journal of Mining Science, vol. 27, no. 5, pp. 438-443, 1992.

[18] Y.-c. Yang, J.-w. Zhou, F.-g. Xu, and H.-g. Xing, "An experimental study on the water-induced strength reduction in zigong argillaceous siltstone with different degree of weathering," Advances in Materials Science and Engineering, vol. 2016, Article ID 4956986, 12 pages, 2016.

[19] T. B. Boving and P. Grathwohl, "Tracer diffusion coefficients in sedimentary rocks: correlation to porosity and hydraulic conductivity," Journal of Contaminant Hydrology, vol. 53, no. 1-2, pp. 85-100, 2001.

[20] B. Yang, Y. Luo, D. Jeng, and J. Feng, "Effects of moisture content on the dynamic response and failure mode of unsaturated soil slope subjected to seismic load," Bulletin of the Seismological Society of America, vol. 109, no. 2, pp. 489-504, 2019.

[21] V. H. Nguyen, N. Gland, J. Dautriat, C. David, J. Wassermann, and J. Guélard, "Compaction, permeability evolution and stress path effects in unconsolidated sand and weakly consolidated sandstone," International Journal of Rock Mechanics and Mining Sciences, vol. 67, pp. 226-239, 2014.

[22] K. F. Bizjak and B. Petkovšek, "Displacement analysis of tunnel support in soft rock around a shallow highway tunnel at Golovec," Engineering Geology, vol. 75, no. 1, pp. 89-106, 2004.

[23] B. Liu, H. Yang, and S. Karekal, "Effect of water content on argillization of mudstone during the tunnelling process," Rock Mechanics and Rock Engineering, vol. 53, no. 2, pp. 799-813, 2019.

[24] S. Nakagawa and L. R. Myer, "Mechanical and acoustic properties of weakly cemented granular rocks," Rock Mechanics in the National Interest, vol. 1, no. 2, 2001.

[25] S. Yadav, C. Saldana, and T. G. Murthy, "Experimental investigations on deformation of soft rock during cutting," International Journal of Rock Mechanics and Mining Sciences, vol. 105, pp. 123-132, 2018.

[26] E. Liu and S. He, "Effects of cyclic dynamic loading on the mechanical properties of intact rock samples under confining pressure conditions," Engineering Geology, vol. 125, pp. 81-91, 2012.

[27] Z. Yan, F. Dai, Y. Liu, H. Du, and J. Luo, "Dynamic strength and cracking behaviors of single-flawed rock subjected to coupled static-dynamic compression," Rock Mechanics and Rock Engineering, vol. 53, no. 9, pp. 4289-4298, 2020.

[28] J. Van Itterbeeck, D. J. Horne, P. Bultynck, and $\mathrm{N}$. Vandenberghe, "Stratigraphy and palaeoenvironment of the dinosaur-bearing upper cretaceous iren dabasu formation, inner Mongolia, people's republic of China," Cretaceous Research, vol. 26, no. 4, pp. 699-725, 2005.

[29] H.-Y. Fu, H.-B. Jiang, X. Qiu, Y.-P. Ji, W. Chen, and L. Zeng, "Seepage characteristics of a fractured silty mudstone under different confining pressures and temperatures," Journal of Central South University, vol. 27, no. 7, pp. 1907-1916, 2020.

[30] Q. T. Pham, F. Vales, L. Malinsky, D. Nguyen Minh, and H. Gharbi, "Effects of desaturation-resaturation on mudstone," Physics and Chemistry of the Earth, Parts $A / B / C$, vol. 32, no. 8-14, pp. 646-655, 2007.

[31] A.-U.-R. Tariq and D. S. Durnford, "Analytical volume change model for swelling clay soils," Soil Science Society of America Journal, vol. 57, no. 5, pp. 1183-1187, 1993.

[32] D. Miller, R. Plumb, and G. Boitnott, "Compressive strength and elastic properties of a transversely isotropic calcareous mudstone," Geophysical Prospecting, vol. 61, no. 2, pp. 315-328, 2013.

[33] L. Meng, L. Han, Q. Meng, K. Liu, M. Tian, and H. Zhu, "Study on characteristic and energy of argillaceous weakly cemented rock under dynamic loading by Hopkinson bar experiment," Energies, vol. 13, no. 12, p. 3215, 2020.

[34] W. Chen, B. Zhang, and M. J. Forrestal, "A split Hopkinson bar technique for low-impedance materials," Experimental Mechanics, vol. 39, no. 2, pp. 81-85, 1999.

[35] B. A. Gama, S. L. Lopatnikov, and J. W. Gillespie, "Hopkinson bar experimental technique: a critical review," Applied Mechanics Reviews, vol. 57, no. 4, pp. 223-250, 2004.

[36] Y. Xu, F. Dai, and H. Du, "Experimental and numerical studies on compression-shear behaviors of brittle rocks subjected to combined static-dynamic loading," International Journal of Mechanical Sciences, vol. 175, Article ID 105520, 2020.

[37] G. Challita and R. Othman, "Finite-element analysis of SHPB tests on double-lap adhesive joints," International Journal of Adhesion and Adhesives, vol. 30, no. 4, pp. 236-244, 2010.

[38] H.-B. Du, F. Dai, Y. Xu, Z. Yan, and M.-D. Wei, "Mechanical responses and failure mechanism of hydrostatically pressurized rocks under combined compression-shear impacting," International Journal of Mechanical Sciences, vol. 165, Article ID 105219, 2020.

[39] H.-B. Du, F. Dai, Y. Xu, Y. Liu, and H.-N. Xu, "Numerical investigation on the dynamic strength and failure behavior of rocks under hydrostatic confinement in SHPB testing," International Journal of Rock Mechanics and Mining Sciences, vol. 108, pp. 43-57, 2018.

[40] F. Cornet and R. Morin, "Evaluation of hydromechanical coupling in a granite rock mass from a high-volume highpressure injection experiment: le Mayet de Montagne, France," International Journal of Rock Mechanics and Mining Science \& Geomechanics Abstracts, vol. 34, no. 3-4, p. 427, 1997.

[41] A. M. Shehata and H. A. Nasr-El-Din, "The role of sandstone mineralogy and rock quality in the performance of low-salinity waterflooding," SPE Reservoir Evaluation and Engineering, vol. 20, no. 1, pp. 087-106, 2017.

[42] R. Rezaee, A. Saeedi, and B. Clennell, "Tight gas sands permeability estimation from mercury injection capillary pressure and nuclear magnetic resonance data," Journal of Petroleum Science and Engineering, vol. 88-89, pp. 92-99, 2012.

[43] R. Zwiessler, T. Kenkmann, M. H. Poelchau, S. Nau, and S. Hess, "On the use of a split Hopkinson pressure bar in structural geology: high strain rate deformation of seeberger sandstone and carrara marble under uniaxial compression," Journal of Structural Geology, vol. 97, pp. 225-236, 2017.

[44] N. H. Koralegedara and J. B. Maynard, "Chemical, mineralogical and textural properties of the kope formation mudstones: how they affect its durability," Engineering Geology, vol. 228, pp. 312-322, 2017.

[45] Y. Xu and F. Dai, "Dynamic response and failure mechanism of brittle rocks under combined compression-shear loading experiments," Rock Mechanics and Rock Engineering, vol. 51, no. 3, pp. 747-764, 2017.

[46] D. Zheng and Q. Li, "An explanation for rate effect of concrete strength based on fracture toughness including free water viscosity," Engineering Fracture Mechanics, vol. 71, no. 16-17, pp. 2319-2327, 2004. 
[47] L. Callisto and G. Calabresi, "Mechanical behaviour of a natural soft clay," Géotechnique, vol. 48, no. 4, pp. 495-513, 1998.

[48] H. F. Deng, M. L. Zhou, J. L. Li, X. S. Sun, and Y. L. Huang, "Creep degradation mechanism by water-rock interaction in the red-layer soft rock," Arabian Journal of Geosciences, vol. 9, no. 12, 2016. 